\title{
WestVirginiaUniversity
}

THE RESEARCH REPOSITORY @ WVU

Graduate Theses, Dissertations, and Problem Reports

2018

\section{Watching You Watching Me: Lateral Surveillance in Singapore}

Yan Song Lee

Follow this and additional works at: https://researchrepository.wvu.edu/etd

\section{Recommended Citation}

Lee, Yan Song, "Watching You Watching Me: Lateral Surveillance in Singapore" (2018). Graduate Theses, Dissertations, and Problem Reports. 6053.

https://researchrepository.wvu.edu/etd/6053

This Thesis is protected by copyright and/or related rights. It has been brought to you by the The Research Repository @ WVU with permission from the rights-holder(s). You are free to use this Thesis in any way that is permitted by the copyright and related rights legislation that applies to your use. For other uses you must obtain permission from the rights-holder(s) directly, unless additional rights are indicated by a Creative Commons license in the record and/ or on the work itself. This Thesis has been accepted for inclusion in WVU Graduate Theses, Dissertations, and Problem Reports collection by an authorized administrator of The Research Repository @ WVU. For more information, please contact researchrepository@mail.wvu.edu. 


\title{
Watching You Watching Me: Lateral Surveillance in Singapore
}

\author{
Lee Yan Song
}

Thesis submitted

to the Eberly College of Arts and Sciences at

West Virginia University

in partial fulfillment of the requirements for the degree of

Master of Arts in

Sociology

\author{
Corey Colyer, Ph.D., Chair \\ Jason Manning, Ph.D. \\ Jesse Wozniak, Ph.D. \\ Department of Sociology
}

Morgantown, West Virginia

2018

Keywords: Surveillance, Lateral surveillance, Singapore, dashboard cameras, Foucault, risk society, Uber, ridesharing

Copyright 2018 Lee Yan Song 


\section{ABSTRACT \\ Watching You Watching Me: Lateral Surveillance in Singapore \\ Lee Yan Song}

Historically, top-down surveillance - surveillance from the state and other organizations - has dominated social life, but not anymore. Technological advances drove down the price of surveillance equipment which aided in the proliferation of devices such as dashboard cameras. The widespread use of affordable surveillance equipment gave rise to the phenomenon of lateral surveillance, whereby laypersons can employ surveillance techniques to monitor individuals around them. The Singapore metropolis provides an excellent example with the ubiquitous use of dashboard cameras for cars today. In this research, I focus on Singaporean rideshare drivers who are simultaneously subjected to traditional forms of top-down surveillance from rideshare corporations, as well as lateral surveillance from the dashboard cameras of other road users. Contrary to the belief that individuals are always sceptical of surveillance, the respondents on average reported a positive perception of both top-down and lateral surveillance. Using Ulrich Beck's concept of risk society, I posit that an individual's appraisal of a surveillance system is directly related to the amount of risk the surveillance system mitigates for him or her. 


\section{Contents}

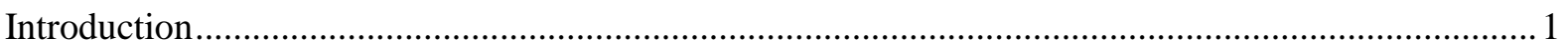

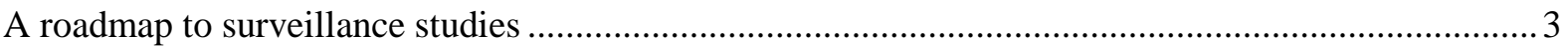

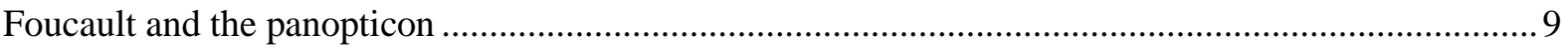

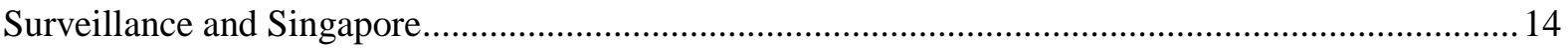

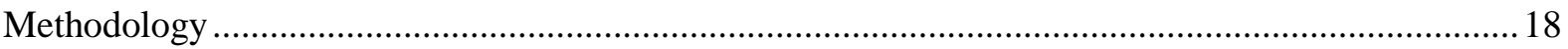

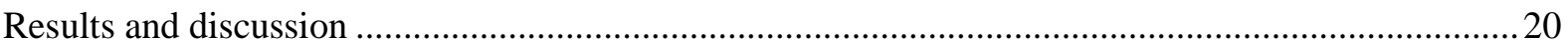

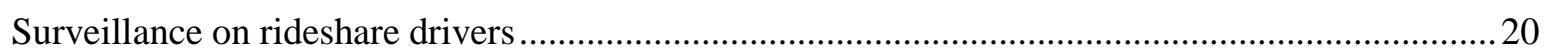

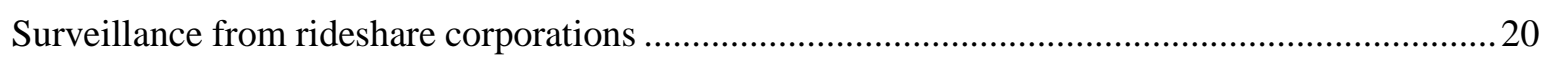

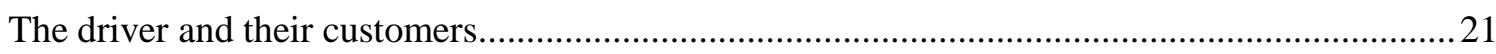

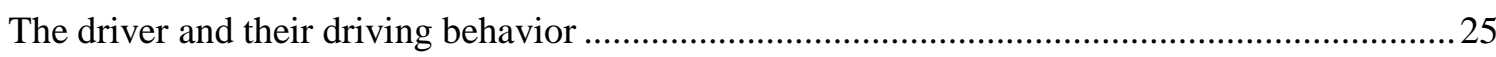

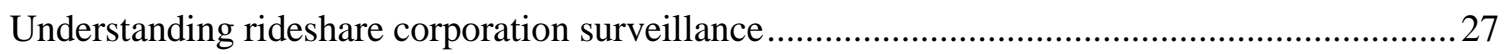

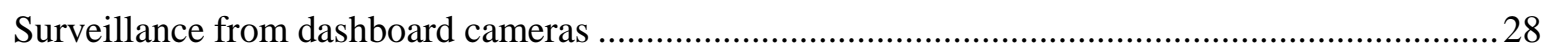

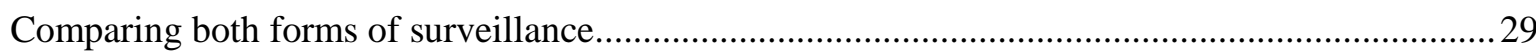

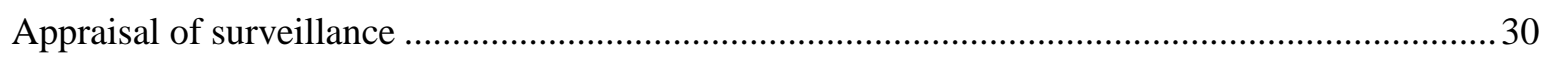

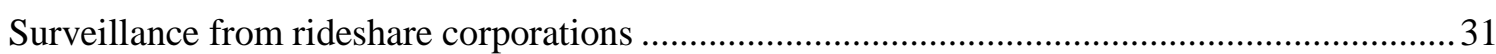

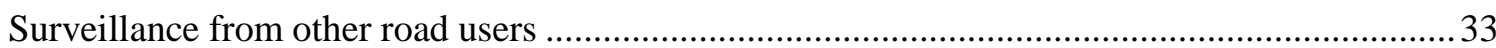

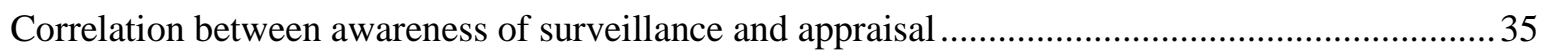

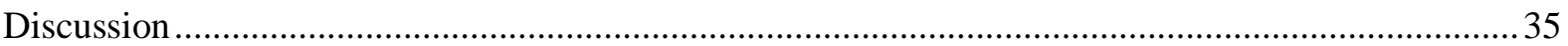

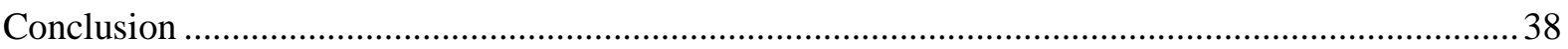

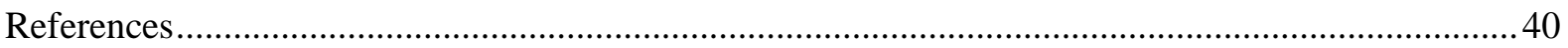




\section{Introduction}

The definition of surveillance comprises of two key components. The first involves collecting data from a delineated group of people and the second requires that there is analysis and mobilization of the collected data to achieve certain goals, be it social, economic, political, etc. (Lyon, Haggerty, and Ball 2012). Rudimentary forms of surveillance involves individuals being the primary data gatherers who were constrained by time and physicality, which curbed the amount of information that could be collected. Since the industrial revolution, the art of surveillance has made great strides forward due to technological innovations which has enabled the systematic collection and processing of data on large numbers of individuals. This change also shifted the normative purpose of surveillance from monitoring specific individuals of significance to the collection of data on entire populations of interest (Lyon 2003). Today, surveillance acts falls into two major typologies - traditional surveillance and new surveillance (Marx 2016). The former relies on the individual's human senses to gather information, think of the typical nosy neighbor listening or watching the on-goings in their estate or exchanging gossip with each other. In this thesis, we are only interested in the latter, new surveillance, which Marx defines as the "scrutiny of individuals, groups, and contexts through the use of technical means to extract or create information" (2016:20). Think of CCTV cameras or data miners that enables or enhances the human capacity or ability to collect or analyze and that without, an individual would never be able to produce with their own human capacities. Since this thesis is solely studying forms of new surveillance and for purposes of simplicity, the word surveillance refers to new surveillance from here on.

When asked to picture what and how surveillance is or occurs, many of us think of sinister individuals, organizations, or social institutions gathering data on the layperson in hopes of controlling or disciplining a population (Semitsu 2011; Slobogin 2008). This is unsurprising as such stereotypical understanding of surveillance for domination from the top- 
down fashion makes for an excellent plotline for popular media consumption. Think about George Orwell's 1984 where citizens are under the constant surveillance from the government who manifests as an omniscient figure called Big Brother and the book's protagonist tries, and ultimately fails, to subvert the government surveillance. Feeding on people's fear and wonder of a total surveillance state stretches into academia too with the apocalyptical writings on the end of privacy (see Rubenfeld 2008; Sykes 1999; Whitaker 2010). To a certain extent, academics concerned about privacy rights should be rightfully disturbed as for decades, largescale gathering and analysis of data could only be done by large social institutions such as governments who have the monetary reserves and technical expertise to embark on such an endeavor. While this form of top-down surveillance continues to exist, this thesis argues that institutions no longer have a monopoly over surveillance as technological breakthroughs made surveillance equipment more affordable and easier to deploy for laypeople, leading to the democratization of surveillance techniques to the masses. The result is the rise to new forms of surveillance that has yet to capture the wider imagination of the public and non-surveillance academics. This thesis is thus an exploration of one such particular new form of surveillance, lateral surveillance. Lateral surveillance has several synonyms such as peer-surveillance or peer-to-peer monitoring, but they all revolve around the concept of individuals incorporating surveillance techniques to monitor each other (Andrejevic 2002).

The recent popularity of dashboard cameras with drivers in Singapore provides us with an excellent potential site to study lateral surveillance. Dashboard cameras are palm-sized devices mounted under the rear-view mirror which record video footage of events occurring in front of the car. These cameras are representative of lateral surveillance as everyday individuals are now able to collect data on each other and to mobilize that data for their own reasons. In this thesis, the focus is on rideshare drivers from Uber and Grab (a local competitor to Uber) as they are in the unique position of being subjected to both forms of surveillance. Top-down 
surveillance from the rideshare corporations and lateral surveillance from the other rideshare drivers. In particular, this thesis seeks to understand how do the layperson perceive and appraise this new form of surveillance in contrast to the orthodox top-down form of surveillance.

\section{A roadmap to surveillance studies}

In the past 40 years, corporate and governmental institutional structures incorporated these new technological advances in data collecting and manipulation that has led to surveillance emerging "as the dominant organizing practice of late modernity" (Lyon et al. 2012:1). In other words, large social institutions and its bureaucrats in modern society has coopted surveillance tools to "overcome historical limitations to vision (and the other senses)" to be able to gain knowledge and manage a population (Lyon et al. 2012:1). For example in policing, there is a shift from low-tech policing such as going undercover or recruiting snitches to high-tech policing with DNA testing and the placement of CCTV cameras (Haggerty 2012). The result of this new organizing practice has led to "downstream social changes in the dynamics of power, identity, institutional practice and interpersonal relations" (Lyon et al. 2012:1) which drew the first surveillance scholars into the field in the 1950s due to "greater awareness of the human rights abuses of colonialism, fascism, and communism and antidemocratic behavior within democratic societies" (Marx 2015:734).

At that time, interest in the field and the corresponding number of surveillance scholars remained small until the events of the 9/11 terror attacks on the World Trade Center in New York City (Hier and Greenberg 2007; Petersen 2012). Gary T. Marx, a prominent pre-9/11 surveillance scholar said that one "could probably fit all the surveillance researchers into a phone booth; now you would need an auditorium" (Monaghan 2006). The terror attacks was the catalyst to the field's growth as the incident led to a sudden and extensive expansion of 
government surveillance by the US government which attracted attention from scholars who were curious and concerned about the expanded government surveillance.

Today, surveillance studies has grown into one of the youngest distinct academic field. The primary professional organization for surveillance scholars, Surveillance Studies Network $^{1}$, who also manages the most prominent academic journal for surveillance research, lists at least 90 scholars who identify themselves as a surveillance scholar (The Surveillance Studies Network 2018). Being such a young field, surveillance scholars originate from more established disciplines which have been around for a longer time such as law, sociology, criminology, communications, cultural studies, science and technology studies, geography, planning, political science/international relations, psychology, history, economics, organization and management studies, business, and philosophy (Marx and Muschert 2007). Despite the ample academic diversity in, Marx and Muschert argued that the field remains multi-disciplinary rather than inter-disciplinary, with scholars from the various fields approaching surveillance with their distinct discipline's characteristics rather than trying to find synergy with other scholars. Its youth gives surveillance studies "egalitarian openness, energy, and contemporaneity and the ability to incorporate rapid changes and new ideas" (Marx 2012:xxvii). On the other hand, the newness of the field results in a lack of consensus amongst scholars on pivotal issues such as a definitive definition of surveillance, Foucault's panopticon as an intellectually useful and appropriate metaphor for the field, what moral standing surveillance scholars should take, etc. Some of these issues will be explored later in this thesis. But first I wish to discuss two disciplines, public health and organization studies, regarding their relation and impressive contributions to surveillance studies and how the work in their fields illuminate important issues that exist in the field of surveillance studies.

\footnotetext{
${ }^{1}$ http://www.surveillance-studies.net/
} 
The biggest practitioner of surveillance research is actually the public health sciences which uses the word surveillance to represent the tracking of diseases (Marx and Muschert 2007). Entering the word 'surveillance' into Google scholar will net you as many articles from the public health sciences as from the social sciences. Practitioners and academics in this field are mostly concerned with reporting statistics and biological aspects of diseases such as malaria (Cullen and Arguin 2014) and antibiotic-resistant bacteria (Zhu, Zhang, and Wang 2008). The social or legal elements are usually in the conclusion with the authors giving recommendations on slowing down the spread of the disease or calling for more mandatory screening. In fact, it is in this area where we find the very first instance of how data can be collected and then mobilized for a purpose, the very definition of surveillance for this paper. In 1854 England, John Snow started collected data in the form of the locations of deaths from cholera on Board Street (Rogers 2013). Once he collected the data, Snow drew a line for each death on a map of Board Street to mark the location of the death. The result was a map that showed a clustering of lines around a water pump in what is today recognized as the very first practice of data visualization. The belief in the 1850s was that cholera spread through the air and Snow's data on the map showed that the deaths clustered around the pump which suggested an alternate, and correct, hypothesis that cholera is actually spread through contaminated water. This story illustrates the positive powers of surveillance and is segue into the contentious debate today of how surveillance scholars should treat the phenomenon of surveillance.

A major cleavage that exists in the field today lies on the basis of the morality of surveillance - one side takes the position that surveillance should always be morally suspect while the other argues that surveillance is a neutral occurrence and that can be used to both good and bad ends. Academics in the former group generally envision a dystopia where the spread of surveillance is unstoppable, leading to the end of privacy and absolute governmental control over the population (see Semitsu 2011; Slobogin 2008). Some even argue that the 
definition of surveillance has to entail some instance of negative connotation because without it, most of what academics would deem to be surveillance is simply information gathering and is thus too general (Fuchs 2011a). Scholars in this camp thus tend to be more advocative in their scholarly work and see their research as a means to an end goal of emancipating humanity from oppression or dehumanization that can occur with surveillance; a position that many sociologists view their profession to be (Smith 2014).

On the other hand, other surveillance scholars have held on to their stance that surveillance should be studied without such negative pre-conceived notions. Marx's stance is that surveillance itself is neither positive nor negative, it is in its implementation and the situational context that gives rise to the ethical concerns (Marx 2016). His position is built off the argument of David Lyon (2001), one of the first proponents of a neutral approach to surveillance. He posited that surveillance is Janus-faced with good and bad aspects. Surveillance can be used positively in reducing bank robberies with CCTV cameras or in public health as illustrated with Jon Snow. At the same time, surveillance has the "capacity to reinforce social and economic divisions, to channel choices and to direct desires, and even, at its sharp end, to constrain and control" (Lyon 2001:4). While the debate continues in the field, the position of this paper is more aligned towards Lyon and Marx as it makes the argument that lateral surveillance is a double-edged sword. On one hand giving drivers financial protection in an accident if they are not at fault in the form of raw video footage, while on the flip side giving individuals the ability to shame other drivers by uploading the recording onto the Internet.

Another area that has done incidental research in surveillance prior to the growth of the field today is in organizational studies as surveillance is part of how organizations, especially workplaces, maintain discipline and efficient production in a capitalistic economy. The grandfather of organizational studies, Frederick Taylor (1911) whose theory of scientific 
management relies on surveillance to be able to be executed. At its very core, scientific management calls on the management to study and record (in other words, surveil) the productivity of a worker working at maximum efficiency, and then base a worker's wage off that level of productivity. In the following decades, academics such as Sewell (1998), have actually identified instances of lateral surveillance, albeit coined the term differently, years before it was documented in surveillance studies. In his paper, Sewell studied a company that had a surveillance system which comprised of a vertical surveillance from the employers (traditional surveillance) and horizontal surveillance from colleagues (lateral surveillance). He posited that the synergy between both systems of surveillance resulted in increased discipline and control of the worker. The key strength of organizational studies is in their ability to produce explanatory theories. Theories that offer us propositions that explicates a relationship between two different concepts (Homans 1967; Manning 2013). For example, William Rushing (1966) wrote a journal article with several propositions on the relationship of organizational rules and surveillance in relation to other variables such as surveillance will increase when members of the organization perform below expectations.

The field of surveillance studies currently suffers from the lack of such explanatory theories. In fact, a surveillance book titled Theorizing Surveillance: The Panopticon and Beyond disappointingly does not contain a shred of explanatory theory other than Lyon's offhanded, and untested, proposition in his introduction that "the more stringent and rigorous the panoptic regime, the more it generates active resistance, whereas the more soft and subtle the panoptic strategies, the more it produces the desired docile bodies" (Lyon 2006:2). Most surveillance literature today, be it journal articles or books, fall under two major categories the surveillance essay or focused empirical inquiry (Marx 2016). The former seeks to develop grand theories to offer its readers an understanding of how the world operates with respect to surveillance. While this sort of works orientates us to view the world in a certain way, they are 
too board and rarely do they offer us statements or hypotheses that are useful research-wise. Some examples of these sort of work include understanding surveillance as social sorting (Lyon 2003) which argues that surveillance tends to reproduce and amplify social inequalities; or liquid surveillance (Bauman and Lyon 2013) where the authors discuss the implications of surveillance in the postmodern world. On the other hand, academic papers that fall under the focused empirical inquiry typically hinges on a single, contemporary phenomenon of surveillance. While documenting cutting-edge forms of surveillance is important and at times make for an interesting read, such writings are "divorced from larger questions and too often unaware of research in nearby fields" (Marx 2016:14). Examples of these kind of work include in-depth explorations of drones (Wall and Monahan 2011), social media (Trottier 2016), selftracking practices (Sharon and Zandbergen 2016), and even windsurfers who speed-surf (Palmas 2015).

Like Marx (2016), I advocate for the development of more middle-range theories. First mooted by Robert K. Merton (1968) as a more appropriate and useful approach to theory construction as compared to the more popular general social theorizing of that time. In this approach, researchers would begin with the empirical evidence and abstract from it propositions that can be tested or verified with data. The result is the production of explanatory theories as mentioned above, which not only explain why things happen and thus enhance our understanding of the social world but also allow us to predict when something will happen; making explanatory theories very practical to academics and laypeople. Admittedly, this thesis fails to live up to the standard of a middle-range theory and is written more in the style of a focused empirical inquiry. Nevertheless, with the thesis's findings, I will offer several testable propositions in the conclusion which I look forward to investigating in my future dissertation. 


\section{Foucault and the panopticon}

Till today, surveillance scholars typically draw on the work of Michel Foucault and his array of concepts. Although Foucault was not strictly a surveillance scholar, his conceptual work over the course of his career incorporates and requires a system of surveillance for his propositions to operate (Foucault 1991, 1975). Discipline and Punish (Foucault 1975) in particular is Foucault's first foray into surveillance and one that scholars frequently refer to. In his book, Foucault described how modernity is characterized by the change in the primary form of power from sovereign power to disciplinary power. This is very much due to the Enlightenment that swept across Europe and led to calls for a gentler society that relied less on physical threats and torture and more on reformation. Foucault documented how reformists campaigned against using coercive means to make people behave (sovereign power) and pushed for states to manage deviance differently by getting deviant individuals to internalize the correct ways to behave (disciplinary power).

This thesis is especially interested in disciplinary power, it is a form of power that is relatively subtle as it is diffused throughout society and operates through the individual actor who is socialized or trained in what is the expected behavior in that particular situation and would "watch" and regulate their own actions accordingly. A contemporary example in academia is the use of proper and particular methods of citation in any and all of our scholarly work. While there are obvious repercussions for not citing or plagiarizing, there is no need for outright threats or the constant reminder of these repercussions from the dean, department chair, or a journal editor (sovereign power) to ensure that the majority of academics continue reproducing this behavior. This is because such behavior has been internalized so well by academics that they do it automatically and without a second thought, even if they do not cite as they write, most would never attempt to publish any uncited piece of work (disciplinary power). Foucault argues that disciplinary power and the creation of these docile individuals 
requires two crucial steps - the first is to have a system of surveillance to monitor and collect data from the population of interest. The second involves correcting any deviation from the established normative behavior.

Foucault uses the panopticon as the structure necessary to establish a surveillance system that has a hierarchal relationship between the prison guards and the prisoners. The prison guards are placed in a watchtower in the center of the facility and are able to watch over the individual prisoners who could neither see the guards nor know if they are being watched at any given time. This characteristic is crucial as if the prisoners knew when the guards were watching, they would only be compliant when they are being watched. This top-down relationship between the guards and the prisoners allowed the guards to get the prisoners to internalize the normalized behaviors that the guards have come to expect of them. Once the prisoners have internalized the rules of the prison, they are then said to be disciplined, wherein the prisoners themselves automatically behave in the "correct" manner regardless of whether they are being watched or not. Once prisoners internalize the "right" behaviors, "power no longer needs to unleash its sanctions and instead its objects take it upon themselves to behave in the desired manner...power relations involved are, automated and objective...the perfection of power should tend to render its actual exercise unnecessary" (Garland 1990:146).

Today, surveillance scholars frequently debate over the relevance of the panopticon as a metaphor, and subsequently Foucault's assertions regarding discipline (Wood 2007). Haggerty (2006) provides a thorough critique on how the panopticon fails scholarly work as a concept in seven aspects. First, the purpose of surveillance is not only about social control or the discipline of the masses. Outside of prisons, Haggerty states that surveillance can be used for entertainment, consumption, disease management, etc. The panopticon forces the scholar to focus too much attention on social control when it comes to surveillance, limiting the field's potential in understanding the full range of surveillance usages in the real world. Secondly is 
the issue of visibility, or the direction of the gaze. In the panopticon the direction of the gaze is top-down, from the guards to the prisoners. In our world today, visibility can vary between surveillance systems and does not necessary need to be unidirectional and such forms of surveillance is the crux of this thesis. Another issue is the subject/object that is under surveillance. In a panopticon, the targets of surveillance are only human prisoners whereas in the real world, the target of surveillance is not limited to human beings. The healthcare profession uses surveillance extensively to track viruses and zoologists uses tracking devices on endangered animals too.

On the flip side, we also need to question who the watchers are and the ability of the watchers to act on the watched. In the panopticon, the guards are not only able to watch over the prisoners but are also capable of using the knowledge they gained from their surveillance due to pre-existing power arrangement between them and the prisoners. This might not be the same in reality, for example, governments and corporations might be snooping through our emails but the former's surveillance has more and different implications to our lives than the latter's. Furthermore, technological progress has made it so that computers, rather than human beings, are playing a bigger role when it comes to watching and sifting through the data collected to identify individuals of interest.

Another point of critique is the dynamics of surveillance, that surveillance creates disciplined prisoners only when they are "conscious that they are under scrutiny" (Haggerty 2006:34). Haggerty argues that people are largely oblivious to the scrutiny they are subjected to. Moreover, the prisoners in the panopticon are largely passive individuals and human beings in reality have agency and would react to being surveilled. His fifth contention is regarding the normative coding of surveillance, especially within the panopticon. Foucault was adamant about how surveillance and visibility is morally evil in a panopticon and his orientation has continued to exist today with how many scholars continue to assume that surveillance is 
something we should be critical about. While surveillance can be a bad thing, it is better to view it as a double-edged sword as there can be ameliorative effects too, such as contact-tracing when it comes to disease surveillance. Lastly, Haggerty points out that Foucault's writing can be convoluted to his reader and made worse as it had been translated from French. This results in multiple, and oftentimes contradictory, interpretations of his work.

This thesis is interested in two of Haggerty's critiques. First regarding the scholarly assumption that the direction of the surveillant gaze is unidirectional and secondly, the stereotype that the watched are always docile subjects that lack agency. Firstly, in the panopticon, the gaze is unidirectional from the minority guards to the prisoner masses in a topdown fashion. Scholars have also recognized that there are cases in which the surveillant gaze can be flipped in a synopticon (Mathiesen 1997) where the many watch the few in a form of bottom-up surveillance termed sousveillance (Mann, Nolan, and Wellman 2002). As mentioned earlier, there is thus a third way to typify the surveillant gaze, whereby the watchers and the watched stand on a level playing field as in the case of lateral surveillance whereby laypeople utilize surveillance techniques and equipment to monitor other individuals around them who they themselves are monitoring others too (Andrejevic 2006). Ganesh (2016) argues that this shift towards the individual, rather than organizations, as the main user of surveillance is called surveillant individualism which hinges on Fuchs (2011b) concept of prosumption whereby the production and consumption of surveillance is carried out by the individual. Meaning to say that the individual not only conducts the gathering of data, but also mobilizes the collected data that he or she collected themselves for their own causes.

The defining difference between top-down surveillance and lateral surveillance lies in the power relations between the surveiler and the surveiled. Going back to the illustration of the panopticon and its form of top-down surveillance, there exists a power inequality between the prison guards and the prisoner, with the guards holding more power over the prisoners as 
they are able to watch everything that the prisoners are doing and at any time. On the other hand, the prisoners are helpless to the gaze of the prison guards. Power relations in lateral surveillance between the surveiler and the surveiled are more egalitarian. This is because drivers hold dual positions as both the "guard" and the "prisoner" at the same time as they are both monitoring other drivers on the roads whilst being recorded by monitored by other drivers on the roads. With the surveillant gaze and power relations in lateral surveillance different from the top-down forms of surveillance, disciplinary power could function very differently than how Foucault had laid out.

While there are several pieces of literature documenting empirical cases of lateral surveillance, the cases covered in those works do not capture the full two-part definition of surveillance as the (1) collection of data and (2) usage of data towards one's goals. Academic work on how individuals use surveillance techniques to collect data chiefly revolve around governments encouraging their citizens to watch out for threats to public safety (Barnard-Wills 2012; Reeves 2012). In this scenario, citizens are simply an extra pair of "eyes" collecting information for the government or law enforcement, the information collected is simply passed on to the authorities rather than acted upon by the citizens. Moving on, there are then literature covering only second part of the definition of surveillance. Documenting how individuals use data that is already been collected and available to them rather than being users and collectors of data. These can be seen in papers to cover the purchasing background checks on dates (Andrejevic 2006), stalking each other on social media (Marwick 2012), or even simply googling someone online (Andrejevic 2002). This thesis stands out against the current literature as one that explores an empirical example of lateral surveillance that embodies the full definition of what surveillance is, with drivers themselves are collecting data with their dashboard cameras and mobilizing their collected data for their own ends. 
Top-down surveillance and lateral surveillance serve similar roles in the formation of disciplined individuals. Garland (1990) states that surveillance provides the information needed to know whether or not an individual is deviating from the established norm; without a system of surveillance, there is therefore no way for one to catch the deviant. The process of the formation of a disciplined individual involves a constant cycle of catching bad behavior and correcting the bad behavior. Over time, the individual would thus internalize the appropriate behaviors and behave in that manner with or without surveillance. Thus prior to the formation of the disciplined individual, the capabilities of the surveillance system to catch individuals who deviate are factors that lead to the surveillance system's disciplinary power. The key point here is that the individuals being surveilled need to be cognizant that they are being watched for them to develop into disciplined individuals. Haggerty (2006) argues that practically, many individuals go about their daily lives without being self-aware that they are being watched and this would hinder the disciplining effect of surveillance. This is why this thesis is concerned about the level of perception rideshare drivers have of each type of surveillance. Furthermore, we are also interested in how the rideshare drivers appraise each surveillance system, if they perceive them as good or beneficial, the disciplining effect on them would be lessened.

\section{Surveillance and Singapore}

Singaporeans are no strangers to being watched. Since its independence 52 years ago, Singapore's political landscape has been dominated by the People's Action Party. While the party has done much for the country and its citizens, they also spare no effort in consolidating power for themselves and moulding a docile population, what some academics and political pundits call a benevolent dictatorship (Tan 2015) or a nanny state ( $\mathrm{Ng} 2015$; Ortmann 2011). Surveillance of the population is one methods to achieve the government's goals and we can see today that they are the key driver in the proliferation of CCTV cameras and the use of Big 
Data (Au-Yong 2014; Heng 2016; Sim 2016). The government's latest drive to become a "Smart Nation" since 2014 has them deploying cameras and sensors that collect a vast array of data from pedestrian movement to air quality to movement of elderly residents in their homes (Poon 2017; Watts and Purnell 2016). Approximately 80\% of Singaporeans live in public housing and at the end of 2016, all public housing and multi-story carparks that accompany them have been fitted with CCTV cameras (Sim 2016). On top of using surveillance to watch and control the population, the government also views the deployment of surveillance as the solution to preventing unwanted incidents from happening again. Be it to discourage future riots (Y. L. Lim 2013) or to stop wild boar attacks (Lee 2017), every problematic incident that occurs in the island state is usually followed by the deployment of surveillance cameras as an after action remedy.

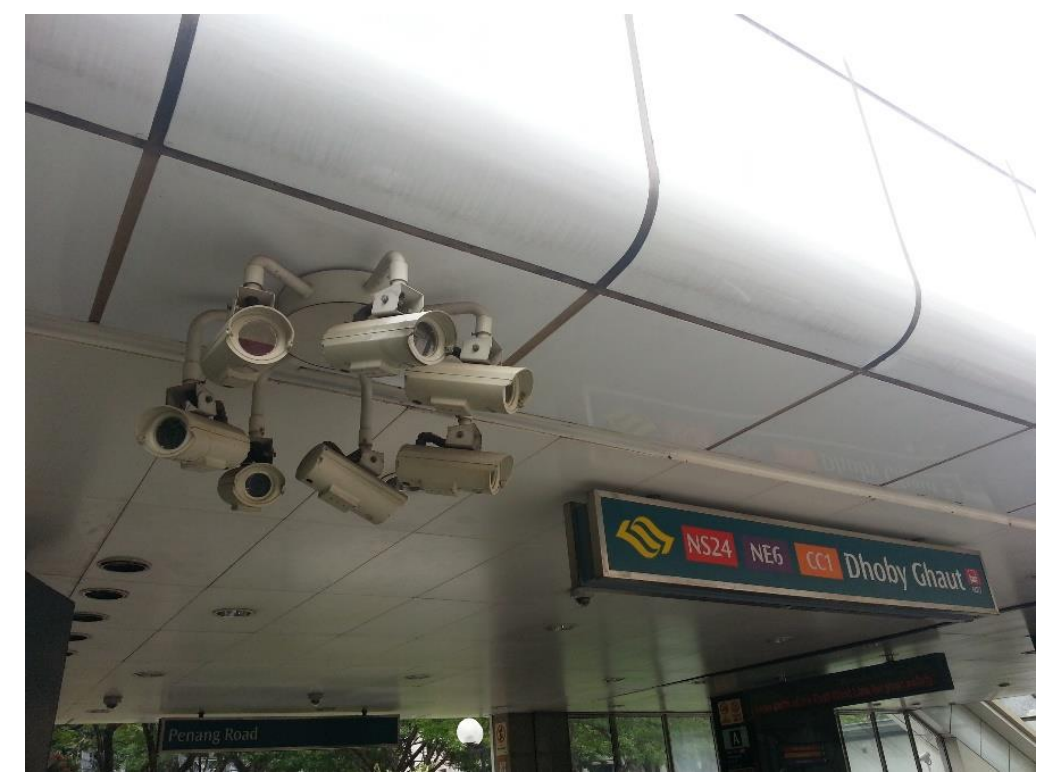

Figure 1. Surveillance cameras outside a downtown metro station in Singapore.

The pervasiveness of surveillance in Singapore, while startling on paper, hardly ever results in any resistance from the population. There are several hypotheses, one could be that the citizens simply trust their government, a survey by Edelman Trust Barometer Index reports that $69 \%$ of Singaporeans say that they trust the government (Goh 2017). Placing it in fifth 
place behind countries such as China (76\%) and Indonesia (71\%) but ahead of other countries such as the US (47\%), UK (36\%), Japan (37\%), Australia (37\%), and South Korea (28\%). Most Singaporeans are not even concerned about government surveillance. Data collected by the World Values Survey in 2012 shows that only 327 and 301 individuals were either "very much" or "a great deal worried" about the government wire-tapping or reading their mail or email. As compared to 489 and 693 individuals who reported that they were "not much" or "not at all" concerned about the same issue (World Values Survey 2016). Despite being cognizant of the government's actions to expand surveillance and the possible problems of a Big Brother state, it could be possible that this minority "believe that to exercise any initiative as a citizen is like trying to defy gravity" (George 2000:127) and thus opt to live with being surveilled, since it has hardly really interfered in their daily lives. This thesis offers a third explanation for the lack of resistance towards surveillance, that Singaporeans themselves truly perceive surveillance as a positive phenomenon.

Returning to the placement of the CCTVs in housing estates, one politician said that "I quite often receive requests to put cameras up. I haven't received any to take cameras down" (Heng 2016). Residents have rationalized the presence of these cameras that they are "okay if they are for safety purposes only" and do not take them as an invasion of their privacy. Even ordinary Singaporeans have adopted the government's attitude that surveillance cameras are the "solution" to societal problems. An estate that started an umbrella sharing scheme based on an honor system was losing umbrellas to thieves. One resident suggested to the reporter that CCTV cameras should be installed as they can deter thieves (Toh 2018). Their perception of the usefulness of CCTV cameras is not without justification. Figures from the police show that the number of unlicensed moneylender harassment cases involving property damage in an area with 2152 blocks fell from 1617 in 2013 to 426 in 2015 (Heng 2016). The footage from these cameras has led to 360 arrests of unlicensed moneylenders due to harassment since 2012. 
The positive perception of surveillance amongst the population has led to a rise in lateral surveillance in Singapore where ordinary citizens are beginning to adopt surveillance techniques into their everyday lives. Besides the popularity of dashboard cameras, another example of lateral surveillance occurs on the metro trains with the use of peoples' mobile phone. Typically, when Singaporeans see anti-social behavior on the metro, such as not giving up one's seat to an elderly or pregnant woman, Singaporeans would take a picture of video of the offending individual. The photo or footage would then be uploaded onto the Internet, most commonly on the citizen journalism site STOMP. Thus to some extent, lateral surveillance has been used by some Singaporeans to shame others around them who are engaging in antisocial behavior (Skoric et al. 2010).

Another possible reason for the eager adoption of surveillance techniques by ordinary Singaporeans can be understood as a reflexive action they have taken as a response to living in a risk society. Ulrich Beck posits that industrialization has brought about new risks to humans (Beck 1992). Sitting in and controlling an enclosed metal container that is moving at 100 kilometers (62 miles) per hour is an experience and an activity that came into existence in the last century. On top of that, cars in Singapore are extremely expensive; a new Toyota Corolla in Singapore cost four times the amount one would have to pay in the United States due the heavy taxes the Singaporean government placed on cars (Naidu-Ghelani 2013). Faced with these risks to one's physical and financial wellbeing, purchasing a dashboard camera that is able to prove innocence in an accident is a small price to pay to mitigate the new risks individuals take on as they enjoy the products of industrialization.

Lateral surveillance with regards to STOMP and other online sites has been studied by Jiow and Morales (2015) which surveyed 223 university students, asking them about their perception of top-down/lateral surveillance and the extent each type of surveillance would deter them from breaking social norms on the metro, bus, or while driving. The paper makes 
the general argument that the students are more aware of and concerned about lateral surveillance than top-down surveillance in all three settings. One critique I have is that, to the best of my knowledge, only a small percentage of students drive every day or frequently. This is due to the high prices of cars in Singapore alongside other car expenses (gas, parking, etc.) (Naidu-Ghelani 2013). Those who drive most likely borrow their parents' car for the weekend. This could be seen in their paper whereby 156 of the 223 respondents reported that they do not drive. Furthermore, the authors also acknowledged that their study leans heavily on the quantitative side and did not ask respondents why they perceived or felt that way about topdown/lateral surveillance. This thesis's focus on rideshare drivers and the emphasis on understanding the person's appraisal of each surveillance type seeks to fill this gap in the literature.

\section{Methodology}

With the aim of producing a more quantitative thesis, the primary method of data collection involved a 10-15 minute web-based survey (see Appendix I). Data collection occurred in two rounds, the first phrase involved working with the rideshare drivers' union in Singapore, the National Private Hire Vehicle Association (NPHVA). Due to prevailing privacy laws in Singapore, the survey was distributed with the help from the staff from NPHVA. In total, they sent three emails, one initial email and two follow-up emails a week a part to encourage participation, to approximately 1000 rideshare drivers who are members of NPHVA. At the end of this phrase, we received a total of 33 usable responses.

Due to the low response rate, it was decided that a second phrase of data collection would be carried out with rideshare driver Facebook groups. Using the search options on Facebook, I searched for key terms such as "Uber", "Grab", and "Singapore" and narrowed the results to Facebook groups only. I was able to identify 16 Facebook groups and gained access to a total of 11 groups (See Appendix II). I posted the link to the survey along with a short 
message asking for their help in participating in the survey. I also made a second reminder post one to two weeks after the initial post. The second round of data collection yielded an additional 14 responses for a total of 47 usable responses for final analysis.

One might notice the very low response rate for this survey, for example the first phrase had a response rate of $3.3 \%$. This thesis is my first attempt at collecting survey results and I had grossly underestimated the unwillingness of Singaporeans to fill surveys. In the second phrase of data collection, it appears that the lack of monetary incentives are the key reason to the poor response rates as seen in the responses of one of my posts in a Facebook group.

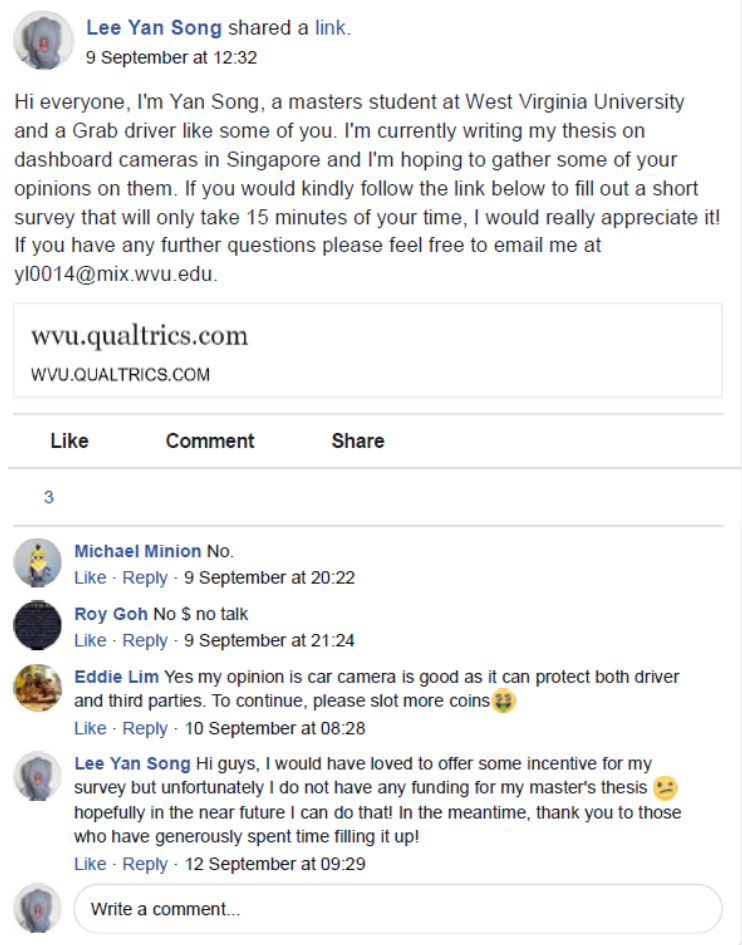

Figure 2. Screenshot of comments I received while soliciting responses in a Facebook group.

While the response rates were disheartening, this experience has made me more knowledgeable and confident of future data collection process with Singaporeans. From now onwards, I know that for my dissertation or even journal papers, should I decided on data collection in the form of surveys, I would need to budget or find funding to provide monetary incentives to my potential respondents. While most might see this as a hurdle towards data 
collection, I see it as a very strong point. Being about to secure the funding for incentivized surveys would ensure that my response rates would actually be very good as Singaporeans are clearly very motivated by money.

In addition, I also did participant observation by signing up as a Grab driver and drove for them for a little over a month from the $31^{\text {st }}$ May 2017 till $3^{\text {rd }}$ July 2017 . While this portion of the research was more participating in the role of a Grab driver than observing since I did not interact with any other Grab drivers during my stint. Nonetheless, putting myself into the shoes of a rideshare driver gave me insights to the level of surveillance Grab had on me. To drive for Grab, I rented a six-seater MPV on a five week contract and had to attend a half a day registration and training session with Grab. Thankfully, I did not encounter any accidents during that period since I ironically did not choose to buy my own dashboard camera.

\section{Results and discussion}

\section{Surveillance on rideshare drivers}

Singapore is a small island nation-state located in South East Asia with a land size roughly equivalent to the five boroughs of New York City. Rideshare drivers in Singapore are under a surprising amount of scrutiny from a variety of sources such as the traffic police, the rideshare corporations, and other drivers. In this thesis the focus is on the latter two sources of surveillance on rideshare drivers.

\section{Surveillance from rideshare corporations}

When discussing surveillance from rideshare corporations in this report, I refer specifically to the two biggest players in the Singaporean market - Uber and Grab, which together make up half of the market for point-to-point transportation (Abdullah 2017). Uber Singapore officially began tracking its drivers in 2016 ( $\mathrm{Lim}$ 2016). The data that both companies collect on their drivers falls into two categories -data on the driver and their customers and data with regards to the driver's driving behavior. 
The driver and their customers

There are four distinct types of data that fall under this subcategory - driver's star rating based on the customer's feedback, booking acceptance rate, booking cancellation rate, and indepth details of each ride given. First of all, one of the key features of these rideshare apps as compared to tradition taxis is that the former allows customers to rate the driver. At the end of each ride, the customer is able to rate the Uber or Grab driver between 1 to 5 stars. While Uber drivers are actually also able to rate their customers, this feature is not available to Grab drivers. As a Grab driver, I can see my driver's rating get updated roughly a few hours after I have completed a trip. Furthermore, I receive weekly emails updating me on what is my rating as compared to the average rating alongside any comments left by my customers (Figure 3 ).

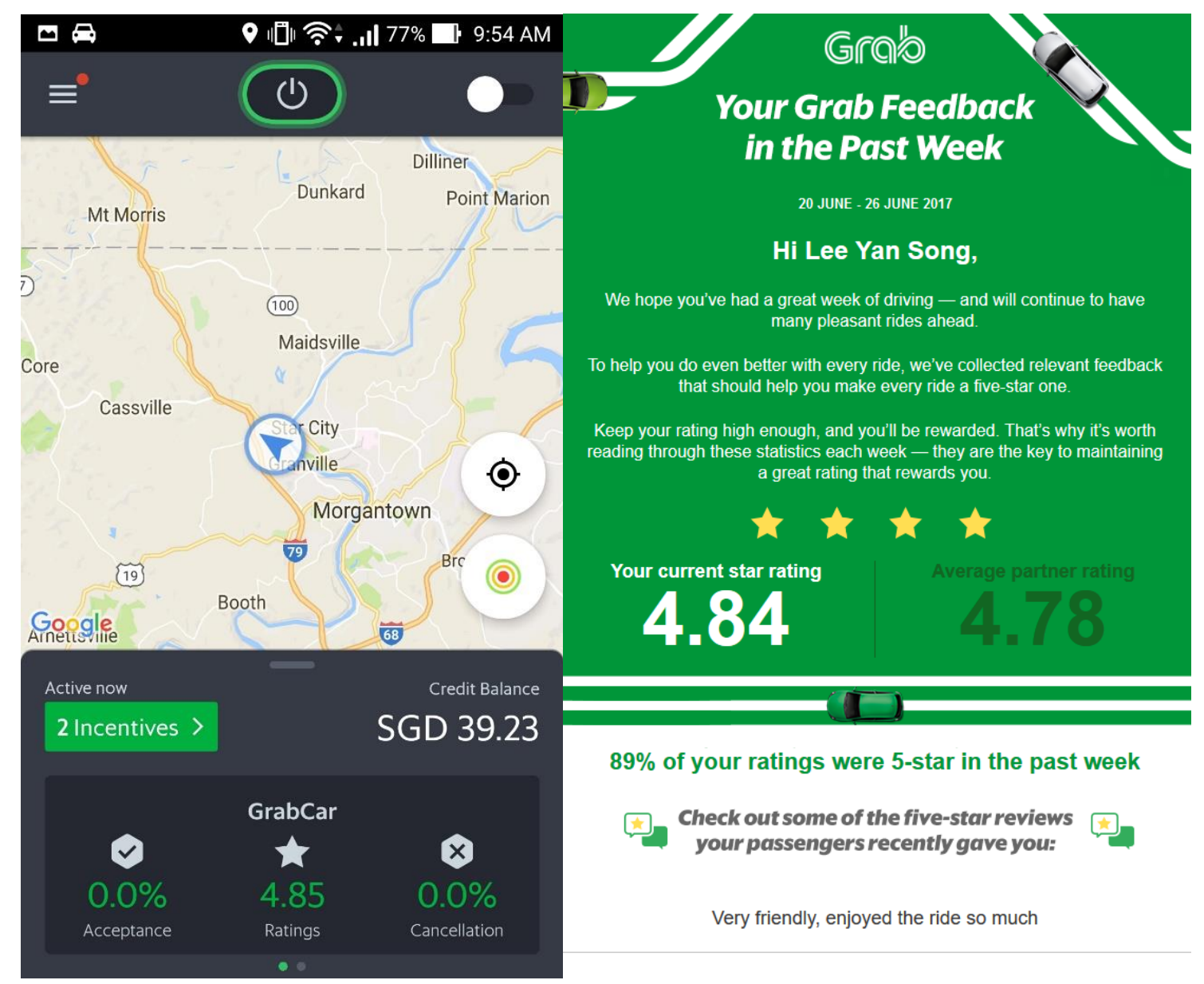

Figure 3. Left: Grab driver's app where one can see one's star rating at the bottom. Right: Weekly email with information about one's current star rating and the average driver's rating alongside any comments received from customers. 
While it might seem intuitive that the star ratings represent surveillance from the customers, it is ultimately surveillance from the rideshare corporation. These individual ratings from each customer should be considered as data points produced by each customer that Uber and Grab collect through their app to be used by them. This information the corporations collect are important to the driver for several reasons. Firstly, if an Uber driver's star rating falls below 4.6, their account is likely to be deactivated (Griswold 2017; Rogers 2015). For Grab, I was told that "if you fall below this rating (4.3 stars). Drivers will receive an SMS should there be some negative feedback from our passengers about their service. The SMS serves as a reminder to improve the service standards". Secondly, one's star rating qualifies the driver for “incentives" from Grab and Uber. Incentives are monetary payouts given by either corporation to the driver, typically for giving a certain amount of rides within a week (Figure 4).

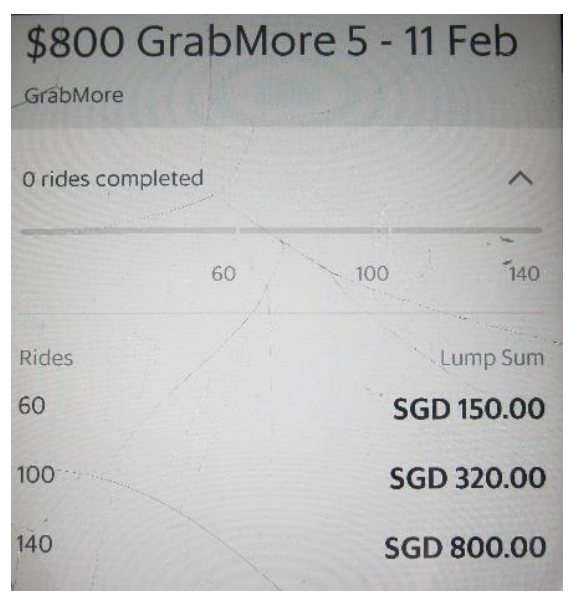

Figure 4. Incentives for the week starting February $5^{\text {th }} 2018$

For Grab drivers, their star rating needs to be 4.3 and above. Along with one's rating, there are two other criteria to meet, one's acceptance rate and cancellation rate, two different types of data that the rideshare corporations collect from their drivers. When a driver turns on their driving app and indicates that they are available to take a job, the server will assign them a job offer and they have ten seconds to accept it (Figure 5). A driver's acceptance rate thus a percentage of the number of job offers they accept. Their cancellation rate is the number of 
jobs they cancel after having accepted a job. As you can see in Figure 6, during my time with Grab, my acceptance rate had to be above $90 \%$ and my cancellation rate below $10 \%$. In other words, one could only refuse to accept and cancel an accepted job 1 in 10 times respectively.

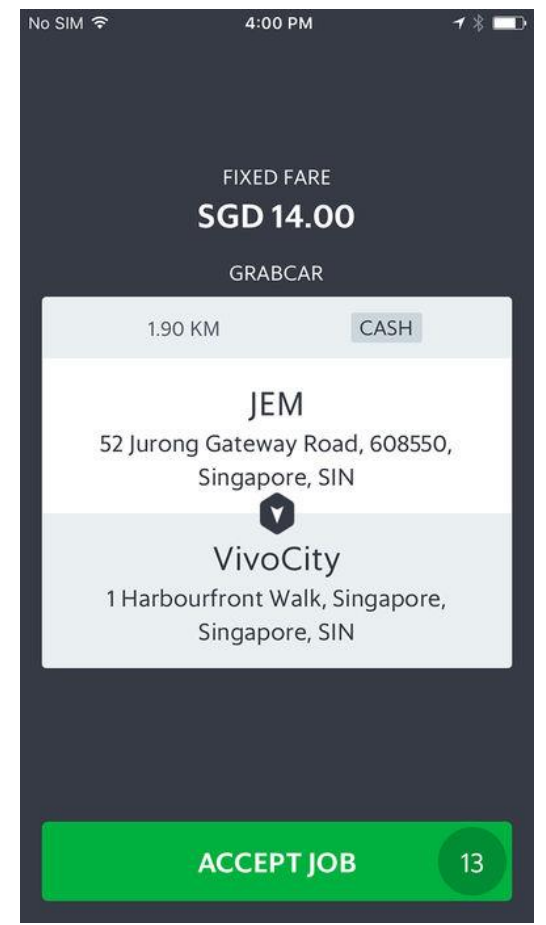

Figure 5. The screen of the Grab driver's app offering the driver a potential job.

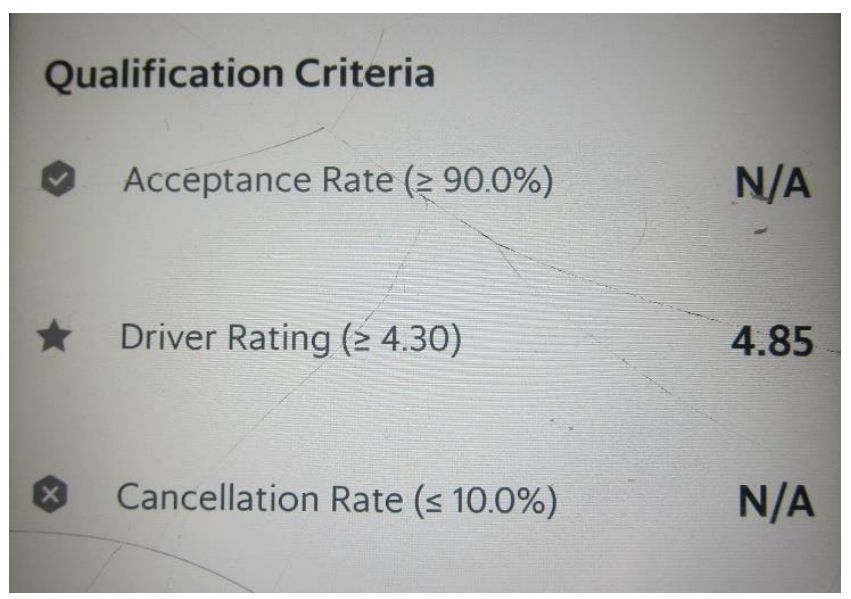

Figure 6. To qualify for the week's incentive a driver has to meet these three criteria.

The rideshare companies give out these incentives to not only attract new drivers but to also in hopes of convincing drivers who drive for their competitor to switch over or to prevent their own drivers from going over to the competitor. For example in Figure 4, to get the 
maximum incentive of $\$ 800$ (\$USD 600) I would have to give 140 within a week. Considering that I give an average of three rides an hour, which is 47 hours of driving or 9-10 hours a day if I drove from Monday to Friday. Thus Grab ensures that I commit most of my week with them rather than their competitor. Needless to say, with such large monetary incentives, it is tempting for several individuals to game the app such as accepting a job and immediately indicating that they have "dropped off" the passenger so as to increase their acceptance rate percentage. To prevent this from happening, the companies thus have to collect accurate data on their drivers. And the data collected is definitely analyzed by the corporations to check for fraud. During my training session with Grab, we were warned not to do that and that individuals have been caught before and permanently terminated. One driver openly posted about his experience trying to cheat the system and ended up being caught and banned (Figure 7). This example goes to show that the data these rideshare corporations gather from their drivers

Picknes Vinayak Veerappan $>$ Uber/Grab
Singapore Riders \& Drivers Sharing
Yesterday at $23: 28$ - ...
GRAB INCENTIVE! Dear fellow Drivers, I drove for
GRAB from April till December 2017 with a car rented
from GRAB RENTALS. In early December, I was
suspended for 2 weeks by GRAB IOs for a violation
(picking and dropping passengers virtually). Many a
times, we face the dilemma of accepting passengers
and having to cancel the trips which results in a
cancellation rate. On that fateful week, I didn't want to
cancel and so started the trip and dropped the
passengers without picking them. Please note that All
AMOUNTS WERE SET TO ZERO. My mistake!
I pleaded with the IOs for leniency but to no avail. As
my car is rented from GR, I had to exclusively drive for
GRAB. So, I asked them about my rental and how I can
be assisted. Immediate reply to me was "sort this out
on your own and speak to GR when you can start
driving". Further, they pressed fabricated stories
saying that I'm rude, unfriendly or quiet. What a joke
when I've been praised for great banters.
After 2 weeks, GR called me pressing for rental arrears
and I told the personnel that I was unable to pay due to
a suspension. I asked if I could pay back by driving
from now onwards. I was declined in an instance. As
such. I volunteered to return the car the followina dav.
O Write a comment...

Figure 7. An individual posting his side of the story in a Facebook group after being caught trying to game the app. 
Finally, Uber and Grab do collect in-depth details of each ride given as seen from my weekly pay statement from Grab below. Uber and Grab might be collecting even more in data than they are sharing with the drivers. It would not be surprising if they also have data on the time and distance of the journey, the route I took to drive, average speed, etc.

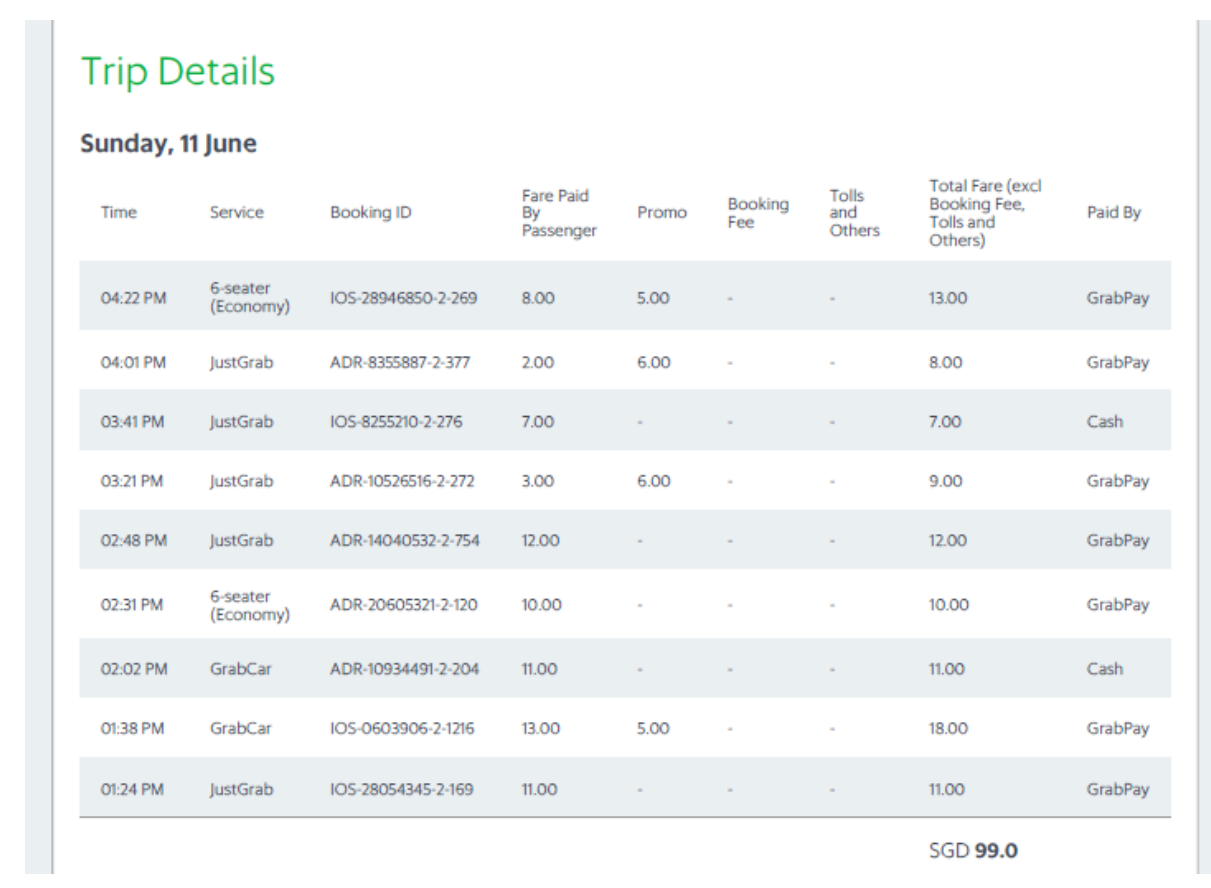

Figure 8. At the end of the week, drivers receive a report with detailed information about the rides they have given in the past week.

The driver and their driving behavior

For Uber drivers, along with their daily summary of their earnings and customer ratings, they also receive information about how well they drove for the day. Data such as the car's speed and how hard drivers brake or accelerate is collected, which is translated into two key driving performance components: the driver's acceleration and braking. Drivers are scored upon the number of times they have accelerated or braked smoothly upon the total number of times they have accelerated or braked as seen in Figure 9 below. 


\section{SAFE DRIVING \\ Driving Report: \\ Wednesday, Nov 09 \\ Smooth Brakes \\ Great work! \\ Smooth Accelerations \\ Great work!

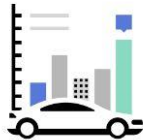 \\ $104 / 118$ \\ $117 / 122$}

Figure 9. Daily report received by an Uber driver regarding their driving

Grab also provides a similar performance report to their drivers, although their reports are weekly rather than daily. Grab's report is slightly different since their reports detail the number of speeding events, average hard braking events, and average sudden acceleration events as seen in Figure 10 below. Further evidence of Grab's interest in surveilling their drivers' driving behaviors occurred in August of 2017 when carmaker Toyota not only decided to invest in Grab but also started a pilot program to have Toyota install its TransLog device in 100 of Grab's rental cars to allow both companies to access more intimate driving data from Grab's drivers (Chin 2017).

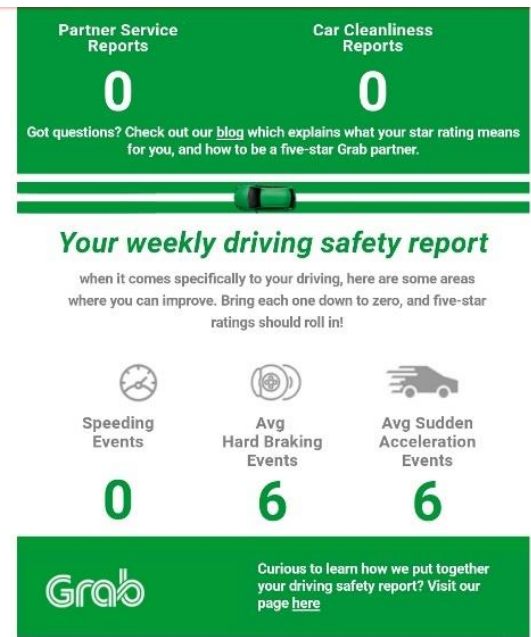

Figure 10. Weekly report from Grab detailing the number of incidents of bad driving 
Understanding rideshare corporation surveillance

Surveillance from the rideshare corporations is an example of a surveillant assemblage (Haggerty and Ericson 2000). Surveillant assemblages are a distinct form of surveillance system whereby rather than recording the individuals of interest as a whole, it gathers separate and distinct bits of information from the individual, "The body is itself, then, an assemblage comprised of myriad component parts and processes which are broken-down for purposes of observation" (Haggerty and Ericson 2000:612-13). And with these separate pieces of data linked to the individual are then pieced back together to form a representation of the individual or the individual's "data double".

In this study, the corporations, rather than putting a video camera to watch over each driver "Big Brother" style, collects separate bits of driver data, the number of times they speed, the number of customers a day, etc. Uber and Grab then are able to combine these discreet pieces of information on their side to create a profile or data double of each driver. We will see in the next section how surveillance from dashboard cameras are different and would be considered "old school" as their dashboard cameras are collecting data that captures the entire individual itself.

There is also a stark contrast in the treatment of both types of data for the rideshare corporations as they only take action on the data regarding customers and not on driving behavior. In August of 2017, 780 taxi drivers were suspended by Grab due to their acceptance rate dropping below 15\% (Lim 2017). With 10,000 taxis driving under the Grab platform, 780 taxis getting banned from Grab represents about $10 \%$ of the population (Au-Yong 2017; Cheng 2017). Following the public outcry, Grab set out an official policy on their driver's acceptance rates (Grab 2018). Insisting that drivers need to keep it at a minimum of $30 \%$ or else the commission rate ( $20 \%$ of the fare paid by the customer is taken by Grab as commission) would increase. After one warning, if the acceptance rate falls between $30 \%$ and 15\%, commission 
rate increases to $30 \%$ and if it is below $15 \%$, the commission rate would be $40 \%$. As for the data on one's bad driving, my own experience and responses from survey participants indicate that no action has been taken on any of them before. Neither has there been any news or anecdotal stories of Uber or Grab taking action against the driver due to driving data collected by either companies.

\section{Surveillance from dashboard cameras}

In addition to surveillance from rideshare corporations, rideshare drivers are also subjected to surveillance from other road users in the form of dashboard cameras. Dashboard cameras are very much like the ones found in police cars in the United States of America (Figure 11). The two key features I want to highlight about these dashboard cameras are that its recording is "always on", meaning to say that the device will start recording the moment the engine starts till the time the engine is turned off, and that most cameras will automatically delete old footage as new footage is recorded, saving the driver the hassle of having to manually delete it (Laukkonen 2016). These two features are highlighted to you to show you how easy it is for the layperson to adopt surveillance techniques into their life with little interference to their daily lives.

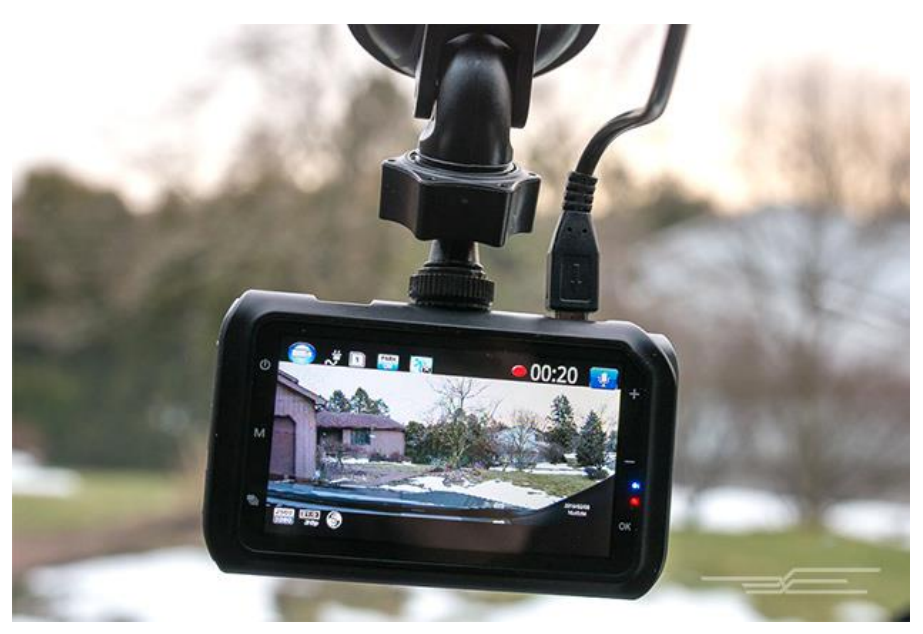

Figure 11. An example of a dashboard camera mounted under the rear-view mirror 
While there is no official number of dashboard cameras in Singapore, there is anecdotal evidence with a popular dashboard camera, Blackvue, whose sales have been increasing by 30\% each year since 2012 (Baharudin 2016b). The popularity of dashboard cameras have even caught the attention of the traffic police who have requested people to send recordings of traffic offenses to them rather than just uploading them to the Internet (Cheong 2015). In 2014 alone, they received over 1000 video clips recorded on these cameras (Hoe 2014). On Internet forums, users have long and elaborate discussions on which dashboard cameras are the best, while some other users share their reviews of dashboard cameras that they are using. Even news outlets are getting into the gig of recommending dashboard cameras (see Yong 2017). In 2013, one in 50 car insurance claims is accompanied with video footage (J. Lim 2013). Videos of reckless drivers or bad driving are usually uploaded onto YouTube, Facebook, or STOMP where one can find often disparaging comments regarding the bad driver who was caught on video (Jiow and Morales 2015). The video quality is usually good enough for one to see the license plate number and no one ever censors the number out.

The phenomenal rise of dashboard cameras is not unique to Singapore. One could say that the Russians were the first to develop a love for dashboard cameras since it first became legitimate in Russia in 2009. Russians primarily use dashboard cameras to protect themselves from insurance claims and corrupt officials in addition to entertainment by uploading footages online (Lavrinc 2013). In the United Kingdom, sales on these cameras shot up by $395 \%$ in 2015, surpassing all other consumer electronic goods (Wood 2016).

\section{Comparing both forms of surveillance}

Data collection from corporations and dashboard cameras are separate systems of surveillance and can be distinguished from each other in a number of ways. The most notable feature between the two is the demarcation of who watches and who are watched. Surveillance from the rideshare corporation is straightforward and unidirectional in that corporations 
scrutinize their drivers, not the other way around. A driver can never truly know what information the corporations are gathering from him/her. They can never know when their data is being looked at or whether action will be taken against them at any point in time.

The distinction between watchers and watched is much more blurred when it comes to the surveillance from other drivers. The argument is that although a driver is subjected to being recorded by another person's dashboard camera, they can also buy their own dashboard camera to surveil the other drivers on the roads. The driver is empowered on their end to be able to "police" bad driving behaviors on the roads. In other words, the other drivers may be watching and recording one's driving behavior, but one can also buy a dashboard camera and watch for bad drivers on the roads. What this means for us is that the relationships between drivers and other road users is much more egalitarian with regards to power than the relationship between the driver and the corporations.

\section{Appraisal of surveillance}

In both instances of surveillance from rideshare corporations and other road users, it is astonishing to find that rideshare drivers have a positive perception of corporate and dashboard surveillance. When compared, drivers have a more positive opinion of surveillance from dashboard cameras than surveillance from the corporations. In fact, none of the respondents have negative opinions of dashboard cameras as seen in Table 1. In this section, I will explore the statistics and also summarize reasons on drivers' viewpoints on both forms of surveillance.

Table 1. Respondent's perceptions of corporate and dashboard surveillance

\begin{tabular}{lcccccc}
\hline & $\mathrm{N}$ & $\begin{array}{c}\text { Very } \\
\text { positive }\end{array}$ & Positive & $\begin{array}{c}\text { Neither } \\
\text { positive or } \\
\text { negative }\end{array}$ & Negative & $\begin{array}{c}\text { Very } \\
\text { negative }\end{array}$ \\
\hline $\begin{array}{l}\text { Appraisal of } \\
\text { surveillance } \\
\text { from } \\
\text { rideshare } \\
\text { corporations }\end{array}$ & 44 & $\begin{array}{c}10 \\
(22.7 \%)\end{array}$ & $\begin{array}{c}18 \\
(40.9 \%)\end{array}$ & $\begin{array}{c}12 \\
(27.3 \%)\end{array}$ & $\begin{array}{c}2 \\
(4.6 \%)\end{array}$ & $\begin{array}{c}(4.6 \%) \\
\end{array}$ \\
\hline
\end{tabular}




\begin{tabular}{|c|c|c|c|c|c|c|}
\hline $\begin{array}{l}\text { Appraisal of } \\
\text { surveillance } \\
\text { from other } \\
\text { drivers }\end{array}$ & 44 & $\begin{array}{c}30 \\
(68.2 \%)\end{array}$ & $\begin{array}{c}13 \\
(29.6 \%)\end{array}$ & $\begin{array}{c}1 \\
(2.3 \%)\end{array}$ & $\begin{array}{c}0 \\
(0 \%)\end{array}$ & $\begin{array}{c}0 \\
(0 \%)\end{array}$ \\
\hline
\end{tabular}

Surveillance from rideshare corporations

Overall, the majority of respondents felt that surveillance from rideshare corporations is a positive occurrence (63.6\%) as compared to those who felt that it was a negative occurrence $(9.2 \%)$ as seen in Figure 12 . There were actually a bigger portion of respondents who felt it was neither good nor bad (27.3\%) than respondents who felt it was a negative occurrence.

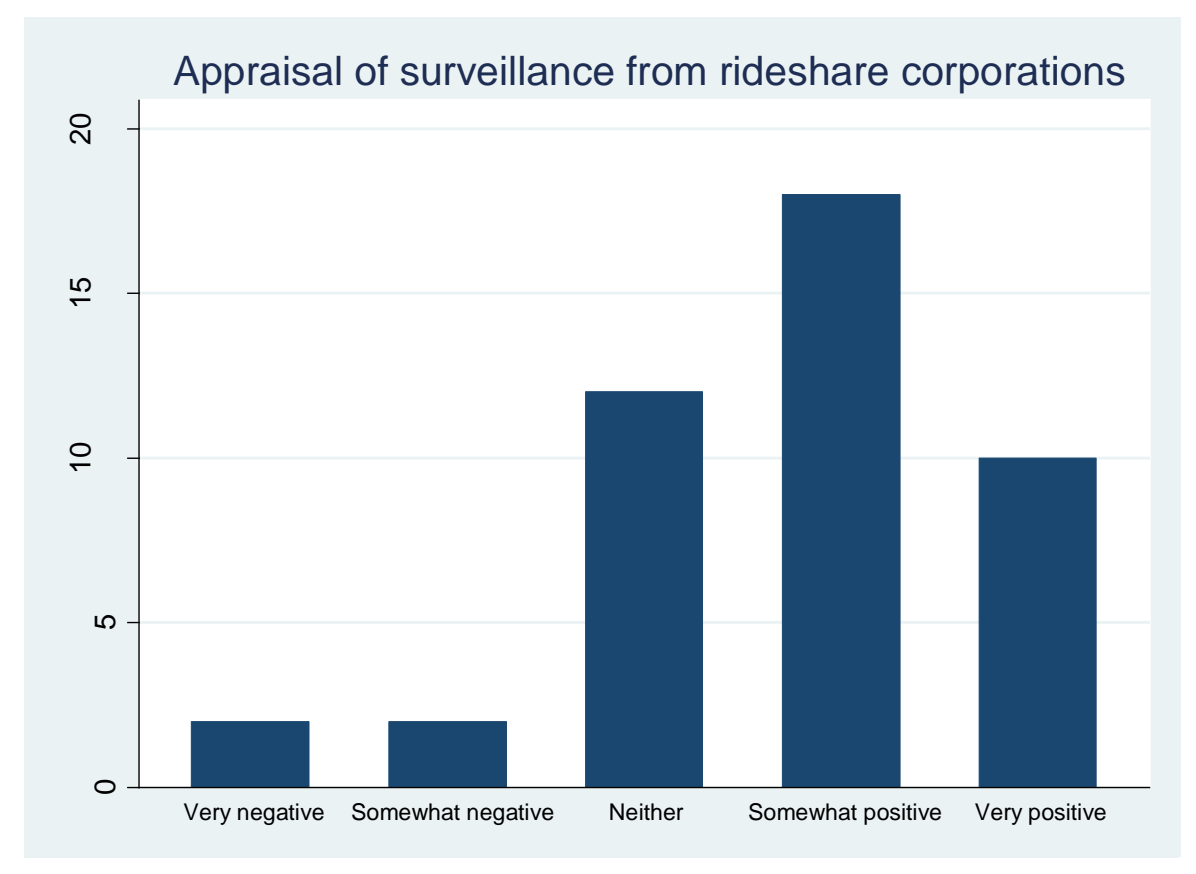

Figure 12. Distribution of respondent's appraisal of surveillance from rideshare corporations.

Survey data show that positive opinions of this form of surveillance cover two core themes of safety and feedback. Regarding safety, one respondent noted how surveillance from the corporations "encourage better driving habits amongst its drivers", while another stated that "it help keep the road safer for all users". Respondents who viewed this form of surveillance 
positively also talked about how this form of surveillance provides feedback to them "as a gauge for our driving".

Negative opinions cover two main topics of inaccuracy and privacy. Some respondents complained that the tracking of their driving lacks context, for example "harsh braking [could be] due to sudden cars cutting into my lane". Furthermore, another drive noted how the individuals managing the tracking data are not drivers and do not understand the day-to-day challenges drivers face. Their response is related to the problems of surveillant assemblages, that data doubles are removed from its original contextual environment and possibly have been reconstructed inaccurately. It is surprising to see that the respondents are cognizant and are able to critique the data collected by the rideshare corporations, showing us that they are not simply passive subjects being observed by Uber and Grab. Privacy concerns were another issue amongst some drivers with one saying that "Uber Grab is supposed to be a ride hailing app company. So why are they tracking us?" and another was cynical stating that these companies are just tracking their drivers to "claim credit [that they are] promoting safety".

One of the respondents who is a more seasoned driver also outlined his knowledge of what the rideshare companies do with the data and how Uber and Grab differs with regards to their surveillance:

"Basically this tracking driver thing is only from Uber. Uber lets you know when you had been speeding or whatever. I know this because when you turn on Google maps through the Uber driver's app with a rider in your car, when you go over the speed limit there is a red speed indicator telling you that you are over the limit. I had done 140kmph (87 mph) with customers inside the car when the speed limit was 90kmph (56 mph). Of course he [the customer] was sleeping and didn't know, but Uber knew. Uber stated before, they are just here to remind you, to stay safe. They don't care how you drive 
lol. Nothing would happen to us drivers. Grab is really amateurish on this aspect. They can't track how fast you are and they don't really care lol. For us drivers we just read and have a good laugh that's all."

\section{Surveillance from other road users}

As seen from Figure 13, all but one respondent felt that dashboard cameras are good with the majority viewing them very positively $(68.2 \%)$. Their justification for their attitude revolved around the benefits of having video evidence and pre-emptively warding off bad drivers and. Multiple respondents also state that having video evidence aids them in making insurance claims by substantiating their account of the sequence of events prior to the accident. Hence reducing the risk drivers are exposed to especially when they can be on the roads for up to 12 hours a day.

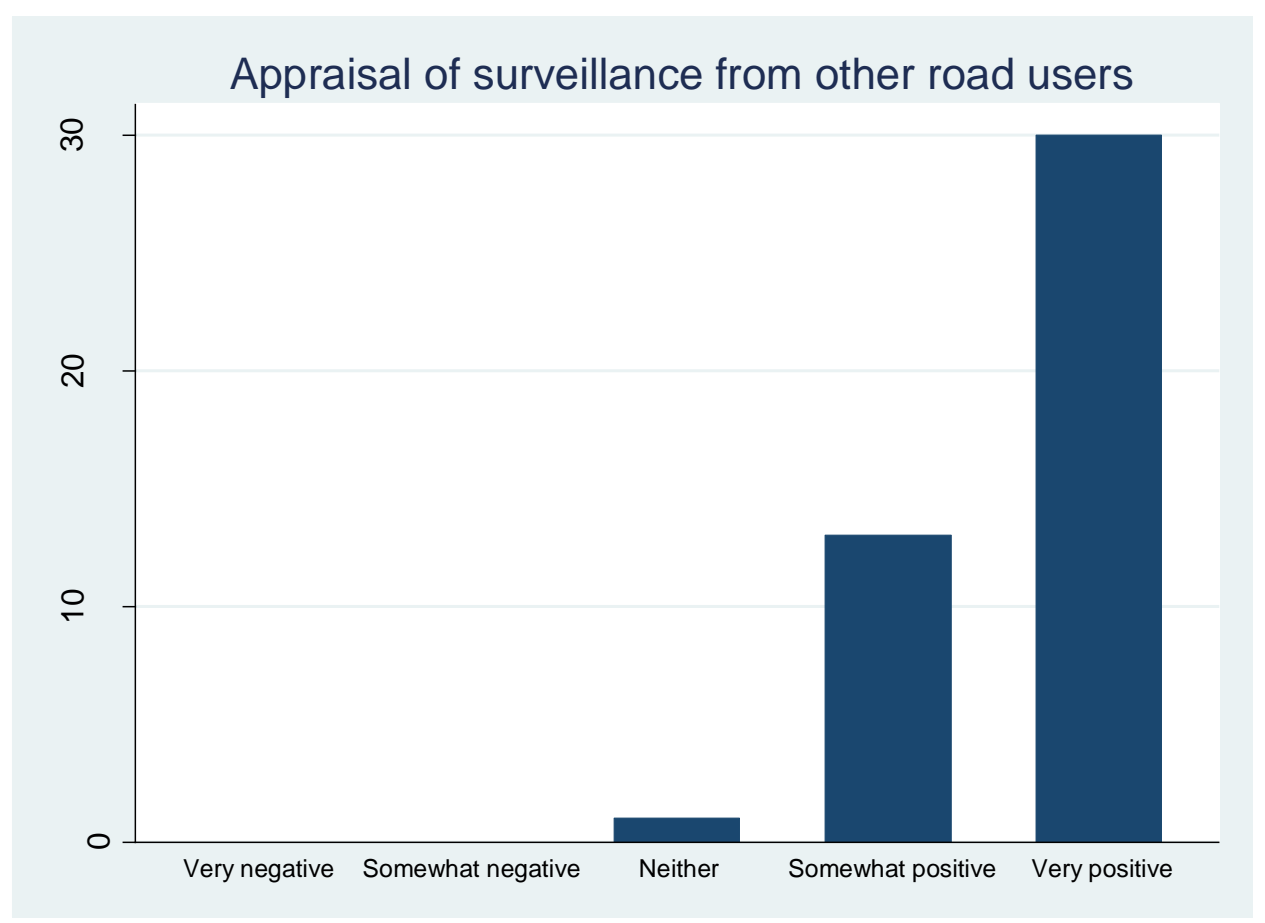

Figure 13. Distribution of respondent's appraisal of surveillance from dashboard cameras.

Several drivers also report that they believe that the presence of dashboard cameras on the roads would scare errant drivers into driving better as "more will drive safely in order to avoid being recorded on cam". In the unfortunate situation of an accident, having a video 
recording of what happened prior to an accident helps to clear up any confusion as "you don't have to argue who is wrong when something happen" and the parties involved could simply refer to the video recording. One respondent gave his account of an accident that he was involved in when he still did not own a dashboard camera and outlined the perils of driving without one:

"I was doing Uberpool with 3 customers from the airport. One was a SQ stewardess and the other two were Filipinos tourist. A female driver in her 50s hit my car in the rear. It was the first time I ever got rear ended. Went to hospital for checks and medical diagnosis. Was awarded \$8200 SGD (\$6205 USD) cash as compensation. Of course, those greedy lawyers demanded $\$ 4000$ (\$3027 USD) as theirs. I did not have a camera, I was so scared that it would be a 50-50 liability and I had to pay excess [also known as deductible, the amount of money to be paid to the rental company for car damages] again even though it wasn't my fault. Luckily the woman had integrity and didn't change her statement nor twist facts. The importance of camera here as the woman could have changed her story and said it was me who was recklessly changing lane. I got rear ended on the back right side of the car. So it was dubious to the insurance companies."

There is even an anecdotal story of a dashboard camera deterring a potential incident of road rage when the other driver saw that the potential victim had a dashboard camera and decided to back away (Baharudin 2016a). Backing up the respondents' assertions that cameras are able to offer a certain level of protection to the driver and ultimately supporting the argument that these drivers perceive and use these dashboard cameras as protection for themselves and their vehicles in a risk society.

There is one individual who felt that dashboard cameras were neither good nor bad. The respondent pointed out how dashboard cameras can be a double-edged sword where it can be 
useful in that "whenever there is an accident there is proof". On the flip side, the respondent noted that it has been used to "abuse and insult other drivers for no reason" referring to public shaming with viral videos on the Internet.

\section{Correlation between awareness of surveillance and appraisal}

Another surprising finding from the survey is that there is a moderate positive correlation between how aware one is of being surveilled by the rideshare corporation and one's appraisal of that form of surveillance $(\mathrm{R}=0.329)$. Meaning to say that as one becomes more aware that Uber or Grab is collecting and analyzing data from them, one would also more likely view this top-down surveillance more favorably.

\section{Discussion}

The key finding of this thesis can be summed up in a single sentence - that Singaporeans generally have a positive opinion of surveillance whether it is in a top-down manner and even more so if it is in the form of lateral surveillance. On the surface level, this finding flies in the face of surveillance scholars who hold a critical view of surveillance. Their position is that surveillance, in any form, is problematic as the spread of surveillance widens the power inequality between the dominators and dominated. Lateral surveillance, in the form of dashboard cameras, clearly illustrates how surveillance can empower the layperson. Dashboard cameras offer the individual an easy technological solution to contest accusations made against them on the roads. Another contradicting finding is that most of the respondents did not find surveillance, from rideshare corporations or dashboard cameras, an invasion of their privacy. In fact, when these individuals are more aware of top-down surveillance, they are more likely to view it in a positive light.

The difference in the respondent's perception of surveillance from rideshare corporations and dashboard cameras can also be explained with the concept of risk society. Arguably, the most important assert for any rideshare driver is his or her car. Losing it in an 
accident not only incurs a loss in the car itself, which is already very expensive, but there is also a loss of livelihood and future earnings. Lateral surveillance, in the form of dashboard camera mitigates more risk to the vehicle as compared to top-down surveillance from the rideshare corporations. As mentioned, the video footage from one's dashboard camera can be, and has been, used as evidence of innocence in a motor accident; whereas data collected through the rideshare corporations is not able to do the same. Therefore, since lateral surveillance is able to mitigate the biggest risk for a rideshare driver, the result is that lateral surveillance is perceived in a more positive light than top-down surveillance. In other words, I posit that an individual's appraisal of a surveillance system is directly related to the amount of risk the surveillance system mitigates for him or her.

Nevertheless, some readers might still be skeptical of these findings and argue that it is possible that Singaporeans have either been socialized to appreciate surveillance or have grown numb to being watched. While my instinct is that it true that the typical Singaporean has grown numb to surveillance in their daily lives, it does not mean that they are apathetic towards surveillance. And that by asking them about their opinions on surveillance in a survey or semistructured interview, their genuine opinions on the phenomenon would be brought to the surface of their conscience. This is one area I would like to explore in greater depth in my future dissertation, more explicitly, how and why Singaporeans are able to make meaning and perceive surveillance in such a positive light that contradicts the general tone of the surveillance literature. Has surveillance scholars grown increasingly disconnected with the real world in our ivory towers?

On top of that, as promised earlier in my literature review, I want to propose several propositions to be tested in my future dissertation. An area that interests me is the comparison of top-down and lateral surveillance in terms of the amount of disciplinary power they exert on the individual. Taking top-down and lateral surveillance and contrasting ideal types, my 
proposition is that as lateral surveillance would exercise a greater amount of disciplinary power than top-down surveillance. The basis of this claim is that in a top-down system, there is one panoptic tower or "Big Brother". Whereas as we move to a more lateral system of surveillance, there will hence be multiple towers or "little brothers" that are able to watch and catch deviant behavior; leading to the individuals to more likely police their own behavior due to the highly likelihood of being caught. This is backed up by a survey research done in Singapore showing that respondents reported lateral surveillance as having more disciplinary power than top-down surveillance (Jiow and Morales 2015). Furthermore, Sewell (1998) posited that the synergy between both systems of surveillance resulted in disciplinary that is greater than each of the system. Leading me to a second proposition that argues that the greatest level of disciplinary power is created when both systems of surveillance are present.

To test this proposition, I hope to be able to carry out a laboratory experiment as it provides the best way to establish causality between the form of surveillance and disciplinary power (Webster and Sell 2014). I propose using a four-condition completely randomized design laboratory experiment, with my target participants being college students. This experiment will be a variation of a public goods game wherein each participant are assigned into a small group and the group's task is to achieve a certain goal collectively. A notable feature we would see is the tension between the participant's self-interest and the group's collective interest.

In my proposed experiment, each participant will be at a computer terminal and randomly assigned to groups of four. Each member will start with $\$ 5$ and the task of the group is to raise a total of $\$ 10$ between the four members, if the total amount is above $\$ 10$, the total amount raised will be divided and returned to each member alongside an extra $\$ 1$ as a reward. If the amount raised is below $\$ 10$, the total amount raised will be forfeited. The group will play a total of five rounds. 
In this CR-4, my four treatment levels are participants being told that 1) their contribution is anonymous (control) 2) experimenter will be informed as to how much you gave (top-down surveillance) 3) other participants will know how much you gave (lateral surveillance) 4) experimenter and other participants will know how much you gave (top-down and lateral surveillance). The dependent variable in this case would actually be the amount each participant contributed, which is also a continuous variable.

\section{Conclusion}

This thesis is simply the beginning of a much longer project to understand surveillance. Two key lessons were learn whilst researching and writing this thesis. First is the intricacies of doing research, especially quantitative research in Singapore and the importance of securing funding to provide monetary incentives to potential Singaporean respondents. My inexperience with recruiting survey respondents has resulted in a less than favorable response rate for my survey and as mentioned above, is primarily due to not offering a financial incentive to complete my survey. The contradictory findings from this thesis has compelled me to want to return to Singapore to gain a better understanding of its unique nature and with this lesson I have learnt, I am confident of collecting better data in the future. Secondly, it was through reading through numerous journal papers and books on surveillance that I have learn that this field sorely lacks explanatory theories which is the nature of it being such a young field. As a second wave of surveillance scholar, I know now to focus my future scholarly work by building upon the current slew of surveillance essays and focused empirical inquiries to create explanatory theories with falsifiable hypotheses.

I foresee my future dissertation to continue to pursue the topic of surveillance in the city-state of Singapore, especially since Singaporeans have a unique and counterintuitive relationship to surveillance. Using the findings from this dissertation, there are two potential key research questions to follow up on at the macro and micro levels. On the macro-scale, one 
could investigate the synergy between lateral surveillance, or even other contemporary forms of surveillance, and more orthodox, panoptic, top-down surveillance methods in governmentality in Singapore. While on the micro-level, one could use qualitative methods to uncover the underlying mechanics that (re)produces the Singaporean society and culture that cultivates individuals who are both uncritical of surveillance and unconcerned with privacy rights. 


\section{References}

Abdullah, Zhaki. 2017. “All Hail the Ride-Hailing Kings.” The Straits Times, May 22. Retrieved November 1, 2017 (http://www.straitstimes.com/singapore/transport/allhail-the-ride-hailing-kings).

Andrejevic, Mark. 2006. "The Discipline of Watching: Detection, Risk, and Lateral Surveillance.” Critical Studies in Media Communication 23(5):391-407.

Andrejevic, Mark. 2002. "The Work of Watching One Another: Lateral Surveillance, Risk, and Governance." Surveillance \& Society 2(4).

Au-Yong, Rachel. 2017. "Tussle between Comfort, Grab Shifts up a Gear.” The Straits Times, October 22. Retrieved March 13, 2018

(http://www.straitstimes.com/singapore/transport/tussle-between-comfort-grab-shiftsup-a-gear).

Au-Yong, Rachel. 2014. "Vision of a Smart Nation Is to Make Life Better: PM Lee." The Straits Times, November 25. Retrieved November 22, 2017 (http://www.straitstimes.com/singapore/vision-of-a-smart-nation-is-to-make-lifebetter-pm-lee).

Baharudin, Hariz. 2016a. "CTE Road Rage Terrors Flee after They Spot Dash Cam." The New Paper, July 17. Retrieved September 2, 2017 (http://www.tnp.sg/news/singapore/cte-road-rage-terrors-flee-after-they-spot-dashcam).

Baharudin, Hariz. 2016b. "Dash Cameras Doing Well." The New Paper, July 17. Retrieved December 6, 2016 (http://www.tnp.sg/news/singapore-news/dash-cameras-doingwell).

Barnard-Wills, David. 2012. Surveillance and Identity: Discourse, Subjectivity and the State. VT: Ashgate.

Bauman, Zygmunt and David Lyon. 2013. Liquid Surveillance: A Conversation. John Wiley \& Sons.

Beck, Ulrich. 1992. Risk Society: Towards a New Modernity. London: SAGE.

Cheng, Kenneth. 2017. “ComfortDelGro's Taxi Fleet Sinks to Lowest in 8 Years, as Grab Recruits over 3,000 Drivers to Its Platform." TODAYonline. Retrieved March 13, 2018 (https://www.todayonline.com/singapore/comfortdelgros-taxi-fleet-sinks-more8-year-low).

Cheong, Danson. 2015. "Submit Clips of Road Offences to Us: Traffic Police." The Straits Times, November 29. Retrieved December 6, 2016 (http://www.straitstimes.com/singapore/submit-clips-of-road-offences-to-us-trafficpolice).

Chin, Yong Chang. 2017. “Toyota Unit Invests in Grab to Power Big Data Push.” August 31. Retrieved September 2, 2017 (http://www.businesstimes.com.sg/transport/toyota-unitinvests-in-grab-to-power-big-data-push). 
Cullen, Karen A. and Paul M. Arguin. 2014. "Malaria Surveillance-United States, 2012." Morbidity and Mortality Weekly Report: Surveillance Summaries 63(12):1-22.

Foucault, Michel. 1975. Discipline and Punish: The Birth of the Prison. NY: Vintage.

Foucault, Michel. 1991. The Foucault Effect: Studies in Governmentality. University of Chicago Press.

Fuchs, Christian. 2011a. “How to Define Surveillance?” MATRIZes 5(1):109-136.

Fuchs, Christian. 2011b. "Web 2.0, Prosumption, and Surveillance." Surveillance \& Society $8(3): 288$.

Ganesh, Shiv. 2016. "Managing Surveillance: Surveillant Individualism in an Era of Relentless Visibility."

Garland, David. 1990. Punishment and Modern Society. Chicago: University of Chicago Press.

George, Cherian. 2000. Singapore: The Air-Conditioned Nation: Essays on the Politics of Comfort and Control, 1990-2000. Singapore: Landmark Books.

Goh, Amanda. 2017. "Trust in Singapore Holds Steady.” Retrieved February 15, 2018 (https://www.edelman.com/post/trust-singapore-holds-steady/).

Grab. 2018. "GrabCar 30\% Minimum Weekly Acceptance Rates (AR) (Starting 8 Jan 2018)." Grab SG. Retrieved February 8, 2018 (https://www.grab.com/sg/car-2/minar/).

Griswold, Alison. 2017. "Uber Is Finally Making Riders Explain Themselves When They Rate a Driver below Five Stars." Quartz, July 25. Retrieved February 8, 2018 (https://qz.com/1038285/uber-will-make-riders-explain-when-they-rate-a-driverbelow-five-stars/).

Haggerty, Kevin D. 2012. "Surveillance, Crime and the Police.” Pp. 235-43 in Routledge Handbook of Surveillance Studies, edited by K. Ball, D. Lyon, and K. D. Haggerty. New York: Routledge.

Haggerty, Kevin D. 2006. "Tear down the Walls: On Demolishing the Panopticon.” Pp. 2345 in Theorizing surveillance: The panopticon and beyond. NY: Routledge.

Haggerty, Kevin D. and Richard V. Ericson. 2000. "The Surveillant Assemblage.” The British Journal of Sociology 51(4):605-622.

Heng, Janice. 2016. "Network of CCTV Cameras Proving Effective." The Straits Times, March 9. Retrieved March 3, 2016 (http://www.straitstimes.com/singapore/networkof-cctv-cameras-proving-effective).

Hier, Sean and Joshua Greenberg. 2007. The Surveillance Studies Reader. McGraw-Hill Education (UK). 
Hoe, Pei Shan. 2014. "More Using In-Car Cameras to Help Track Traffic Offenders." The Straits Times, March 3. Retrieved December 6, 2016 (http://www.straitstimes.com/singapore/more-using-in-car-cameras-to-help-tracktraffic-offenders).

Homans, George Caspar. 1967. The Nature of Social Science. New York: Harcourt, Brace, and World.

Jiow, Hee Jhee and Sofia Morales. 2015. "Lateral Surveillance in Singapore.” Surveillance \& Society 13(3/4):327-37.

Laukkonen, Jeremy. 2016. "What Is a Dashcam?” Lifewire. Retrieved September 2, 2017 (https://www.lifewire.com/what-is-a-dash-camera-534890).

Lavrinc, Damon. 2013. "Why Almost Everyone in Russian Has a Dash Cam." Wired, February 15. Retrieved September 2, 2017 (https://www.wired.com/2013/02/russiandash-cams/).

Lee, Jan. 2017. “Surveillance Cameras Installed after Wild Boar Incidents.” The New Paper, October 24. Retrieved February 9, 2018 (http://www.tnp.sg/news/singapore/surveillance-cameras-installed-after-wild-boarincidents).

Lim, Adrian. 2017. "Some Cabbies Upset by Grab Suspension." The Straits Times, August 9. Retrieved November 1, 2017 (http://www.straitstimes.com/singapore/transport/somecabbies-upset-by-grab-suspension).

Lim, Adrian. 2016. "Uber Tracking How Its Drivers Here Perform." The Straits Times, September 7. Retrieved December 6, 2016 (http://www.straitstimes.com/singapore/transport/uber-tracking-how-its-drivers-hereperform).

Lim, Joyce. 2013. "In-Car Cameras Drive More to Report Offences.” The Straits Times, September 15. Retrieved December 6, 2016 (http://www.straitstimes.com/singapore/in-car-cameras-drive-more-to-reportoffences).

Lim, Yan Liang. 2013. "Little India Riots: Police Install 26 More CCTV Cameras in Race Course, Buffalo Roads." The Straits Times, December 11. Retrieved February 9, 2018 (http://www.straitstimes.com/singapore/little-india-riots-police-install-26-more-cctvcameras-in-race-course-buffalo-roads-0).

Lyon, David. 2003. Surveillance as Social Sorting: Privacy, Risk, and Digital Discrimination. London: Routledge.

Lyon, David. 2001. Surveillance Society: Monitoring Everyday Life. McGraw-Hill Education (UK).

Lyon, David. 2006. Theorizing Surveillance: The Panopticon and Beyond. NY: Routledge. 
Lyon, David, Kevin D. Haggerty, and Kirstie Ball. 2012. "Introducing Surveillance Studies." Pp. 1-11 in Routledge Handbook of Surveillance Studies, edited by K. Ball, D. Lyon, and K. D. Haggerty. New York: Routledge.

Mann, Steve, Jason Nolan, and Barry Wellman. 2002. "Sousveillance: Inventing and Using Wearable Computing Devices for Data Collection in Surveillance Environments." Surveillance \& Society 1(3):331-355.

Manning, Jason. 2013. "Bringing Explanation Back In.” Presented at the annual meeting of North Central Sociological Association, April 5, Indianapolis, Indiana.

Marwick, Alice E. 2012. "The Public Domain: Social Surveillance in Everyday Life.” Surveillance \& Society 9(4):378.

Marx, Gary T. 2015. "Surveillance Studies." International Encyclopedia of the Social \& Behavioral Sciences 23:733-741.

Marx, Gary T. 2016. Windows into the Soul: Surveillance and Society in an Age of High Technology. Chicago: University of Chicago Press.

Marx, Gary T. 2012. “'Your Papers Please': Personal and Professional Encounters with Surveillance." in Routledge Handbook of Surveillance Studies, edited by K. Ball, K. D. Haggerty, and D. Lyon. New York: Routledge.

Marx, Gary T. and Glenn W. Muschert. 2007. "Personal Information, Borders, and the New Surveillance Studies.” Annu. Rev. Law Soc. Sci. 3:375-395.

Mathiesen, Thomas. 1997. "The Viewer Society: Michel Foucault's Panopticon Revisited." Theoretical Criminology 1(2):215-234.

Merton, Robert King. 1968. Social Theory and Social Structure. Simon and Schuster.

Monaghan, Peter. 2006. "Watching the Watchers." Chronicle of Higher Education 52(28):A18.

Naidu-Ghelani, Rajeshni. 2013. "World's Most Expensive Car Market Just Got Pricier." CNBC, March 5. Retrieved March 29, 2017 (http://www.cnbc.com/id/100525565).

Ng, Irene Y. H. 2015. “Being Poor In A Rich 'Nanny State': Developments In Singapore Social Welfare.” The Singapore Economic Review 60(3):1-17.

Ortmann, Stephan. 2011. "Singapore: Authoritarian but Newly Competitive." Journal of Democracy 22(4):153-164.

Palmas, Karl. 2015. "Inauthentically Intense: Coveillance and Consumer Culture among Speedsurfers." Surveillance \& Society 13(3/4):487.

Petersen, Julie K. 2012. Introduction to Surveillance Studies. CRC Press.

Poon, Linda. 2017. "Seeking Privacy in a City of Sensors." CityLab. Retrieved February 9, 2018 (https://www.citylab.com/tech/2017/04/singapore-city-of-sensors/523392/). 
Reeves, Joshua. 2012. "If You See Something, Say Something: Lateral Surveillance and the Uses of Responsibility." Surveillance \& Society 10(3/4):235.

Rogers, Brishen. 2015. "The Social Costs of Uber." University of Chicago Law Review Online 82(1):6.

Rogers, Simon. 2013. "John Snow's Data Journalism: The Cholera Map That Changed the World." The Guardian. Retrieved January 27, 2018

(http://www.theguardian.com/news/datablog/2013/mar/15/john-snow-cholera-map).

Rubenfeld, Jed. 2008. “The End of Privacy.” Stanford Law Review 101-161.

Rushing, William A. 1966. "Organizational Rules and Surveillance: Propositions in Comparative Organizational Analysis.” Administrative Science Quarterly 423-443.

Semitsu, Junichi P. 2011. "From Facebook to Mug Shot: How the Dearth of Social Networking Privacy Rights Revolutionized Online Government Surveillance." Pace Law Review 31(1):291-381.

Sewell, Graham. 1998. "The Discipline of Teams: The Control of Team-Based Industrial Work through Electronic and Peer Surveillance." Administrative Science Quarterly 397-428.

Sharon, Tamar and Dorien Zandbergen. 2016. "From Data Fetishism to Quantifying Selves: Self-Tracking Practices and the Other Values of Data." New Media \& Society 16951709.

Sim, Royston. 2016. "More Surveillance Cameras as Deterrent." The Straits Times, March 19. Retrieved March 3, 2017 (http://www.straitstimes.com/singapore/moresurveillance-cameras-as-deterrent).

Skoric, Marko M., Jia Ping Esther Chua, Meiyan Angeline Liew, Keng Hui Wong, and Pei Jue Yeo. 2010. "Online Shaming in the Asian Context: Community Empowerment or Civic Vigilantism?” Surveillance \& Society 8(2):181-199.

Slobogin, Christopher. 2008. Privacy at Risk: The New Government Surveillance and the Fourth Amendment. Chicago: University of Chicago Press.

Smith, Christian. 2014. The Sacred Project of American Sociology. NY: Oxford University Press.

Sykes, Charles J. 1999. The End of Privacy: The Attack on Personal Rights at Home, at Work, on-Line, and in Court. NY: St. Martin's Press.

Tan, Carlton. 2015. "Lee Kuan Yew Leaves a Legacy of Authoritarian Pragmatism." The Guardian, March 23. Retrieved November 22, 2017 (https://www.theguardian.com/world/2015/mar/23/lee-kuan-yews-legacy-ofauthoritarian-pragmatism-will-serve-singapore-well).

Taylor, Frederick Winslow. 1911. The Principles of Scientific Management. Harper \& Brothers. 
The Surveillance Studies Network. 2018. "Mapping Surveillance Studies." Retrieved January 29, 2018 (http://www.surveillance-studies.net/?p=1122).

Toh, Ee Ming. 2018. "Raining on Their Parade, Ungracious Users Put Dampener on Umbrella-Sharing Project." TODAY, February 11. Retrieved February 12, 2018 (https://www.todayonline.com/singapore/its-raining-their-parade-ungracious-usersput-dampener-umbrella-sharing-project\#.WoDrzzannB0.facebook).

Trottier, Daniel. 2016. Social Media as Surveillance: Rethinking Visibility in a Converging World. Routledge.

Wall, Tyler and Torin Monahan. 2011. "Surveillance and Violence from Afar: The Politics of Drones and Liminal Security-Scapes.” Theoretical Criminology 15(3):239-254.

Watts, Jake Maxwell and Newley Purnell. 2016. "Singapore Is Taking the 'Smart City' to a Whole New Level.” Wall Street Journal, April 25. Retrieved February 9, 2018 (http://www.wsj.com/articles/singapore-is-taking-the-smart-city-to-a-whole-newlevel-1461550026).

Webster, Murray and Jane Sell. 2014. Laboratory Experiments in the Social Sciences. Elsevier.

Whitaker, Reg. 2000. The End of Privacy: How Total Surveillance Is Becoming a Reality. New York: The New Press.

Wood, David M. 2007. "Beyond the Panopticon? Foucault and Surveillance Studies." Pp. 245-63 in Space, knowledge and power: Foucault and geography, edited by J. W. Crampton and S. Elden. New York: Routledge.

Wood, Debbie. 2016. "Dash Cam Sales Grow Faster than Tablets and Digital Cameras in 2015." BusinessCar, September 6. Retrieved September 2, 2017 (http://www.businesscar.co.uk/news/2016/dash-cam-sales-grow-faster-than-tabletsand-digital-cameras-in-2015).

World Values Survey. 2016. "WVS Wave 6 (2010-2014).” Retrieved April 3, 2018 (http://www.worldvaluessurvey.org/WVSDocumentationWV6.jsp).

Yong, Nicholas. 2017. "Dashcams You Should Get for Your Car." Today, February 24. Retrieved July 13, 2017 (http://www.todayonline.com/lifestyle/cars/dashcams-youshould-get-your-car).

Zhu, De-mei, Ying-yuan Zhang, and Fu Wang. 2008. "Surveillance of Bacterial Resistance from Hospitals in Shanghai in 2007." Chinese Journal of Infection and Chemotherapy 6:401-10. 